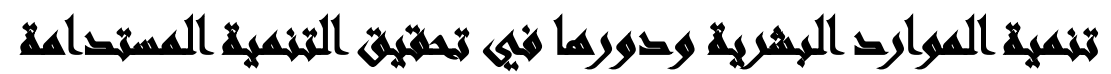

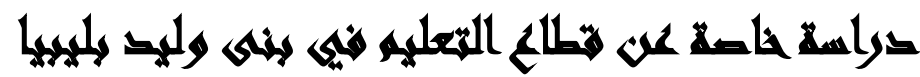

\section{[1T]}

أحمد فؤاد مندور (')- صفاء جرجس تادرس(')- مفتاح محمد عمار (r) أم السعد مريغة صاء تالح

( ) كلية التجارة، جامعة عين شمس r) كلية الاقتصاد والعلوم السياسي، جامعة طرابلس

\section{المستخلئ}

عملية التتمية المستدامة تتضمن تتمية بشرية تهدف إلى تحسين مستوى الرعاية الصحية

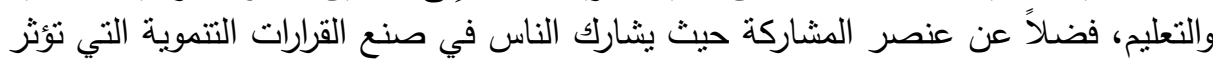

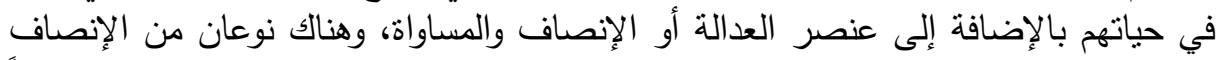

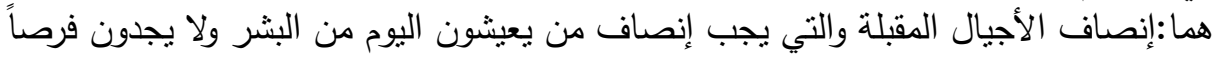

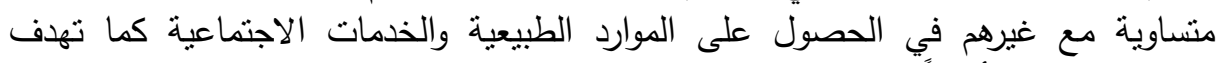

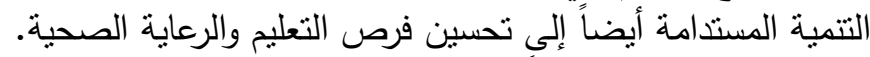

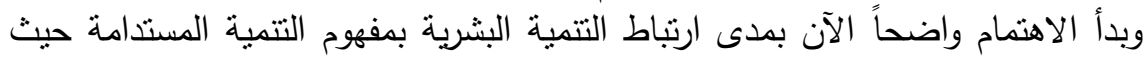

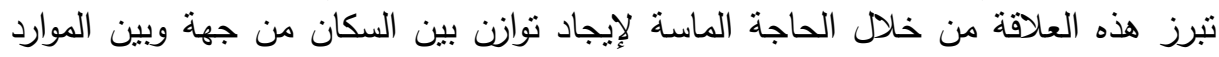

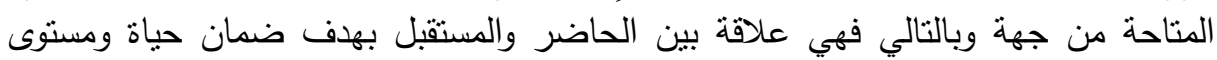

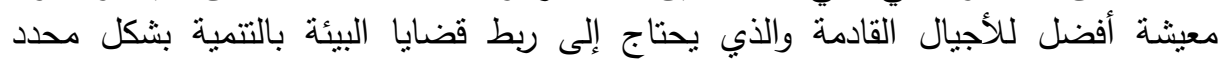
ومستمر حيث إنه لا وجود لتتمية مستدامة بدون التنمية البشرية.

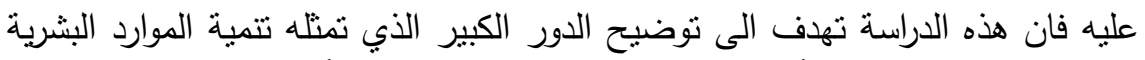

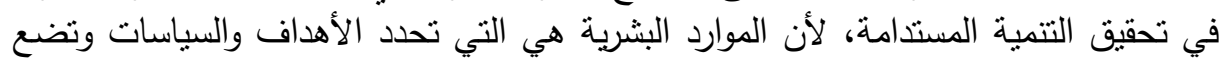

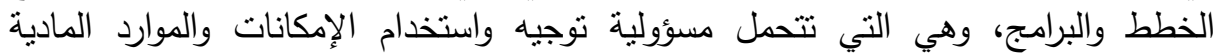

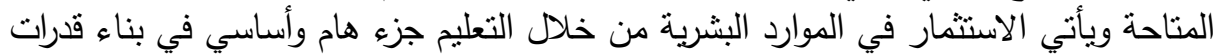

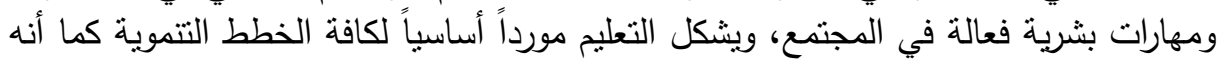

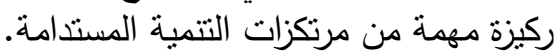

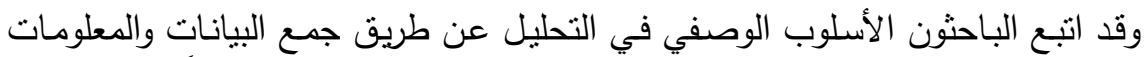

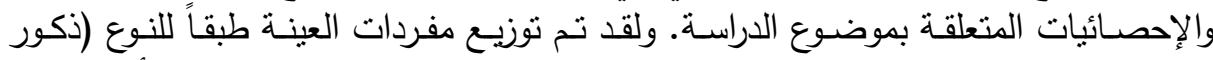

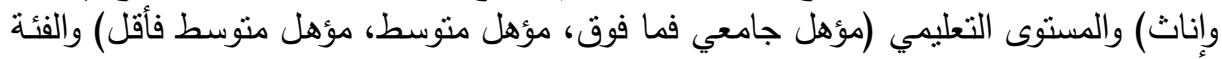

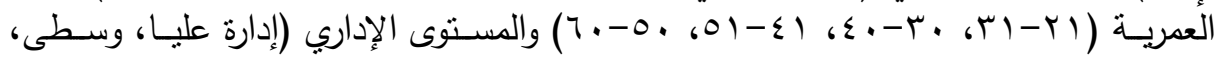
تتفيذية) وعددهم ( ( ) ( ) مفردة. 


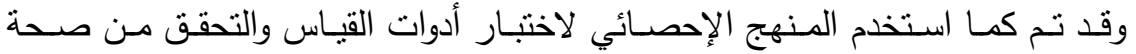

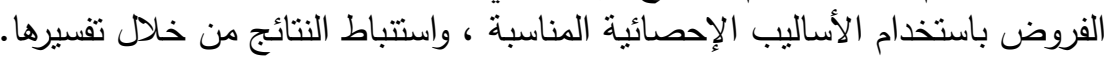

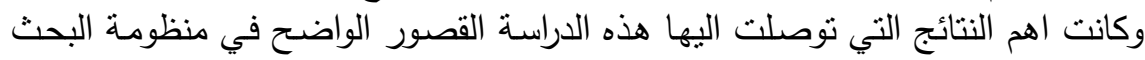

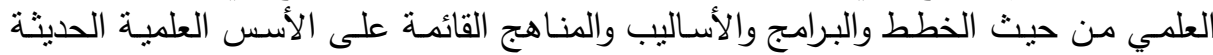
المتعارف عليها وتوافقها مع المتغيرات الاقتصادية والتحديات العالمية والتي يأني في مقدمتها

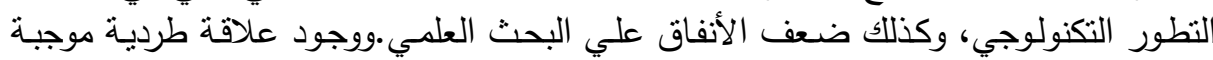
بين كل من بناء خطط وبرامج التعليم المواكبة للثورة التعليمية التتموية وبين كفاءة سياسية التهات إدارة الموارد البشرية في مواكبة متطلبات هذه التبن إنمية. وقد اوصت الدراسة بضرورة اعتبار التعليم والتدريب والبحث العلمي والتتمية التكنولوجية

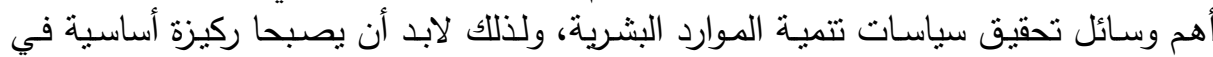

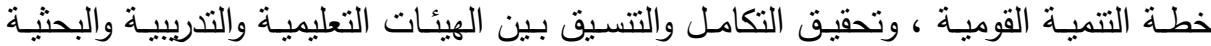

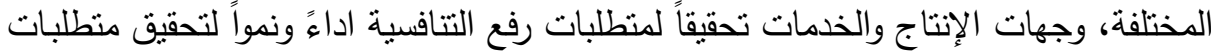

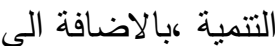

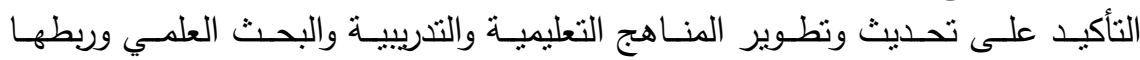
بسياسات نتمية الموارد البشرية المواكبة لمنطلبات التتمية.

\section{rasidl}

أصبحت الموارد البشرية تحتل مركز الصدارة في الاهتمام على مستوى العالم المعاصر

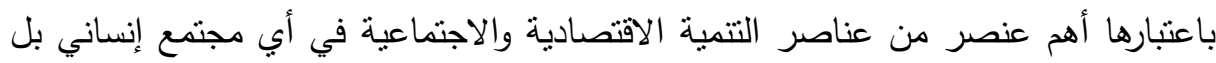

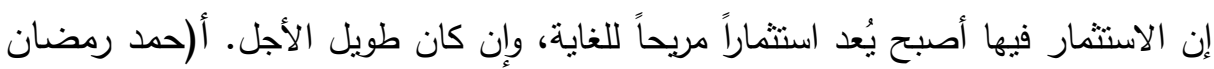

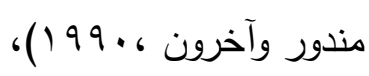

لقد تبلور هذا التأكيد على أهمية الإنسان بشكل جلي بعد صدور (ثورة الأمم) للمفكر البريطاني آدم سميث عام VVY ام، والذي اعتبر أحد أهم التطورات التي أدت إلى الاعتراف

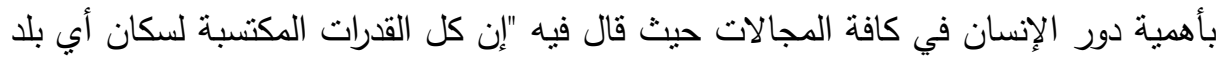
هي جزء من رأسماله"، كما أوضح جون سنيورات كل ذلك في كتابه "مبادئ الاقتصاد

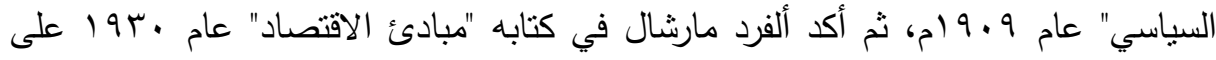

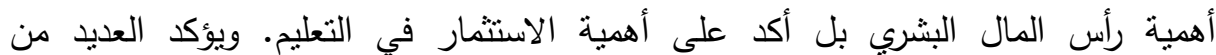


المختصين على أن البداية الجادة للاهنمام باقتصاديات التعليم ورأس المال البشري(. Adam

(Smith ,2005

كانت مطلع الستينات وبالتحديد عندما ألقى ثبودور شولنز محاضرته "الاستثمار في

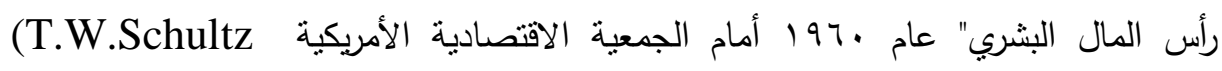

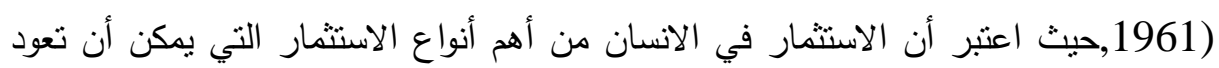

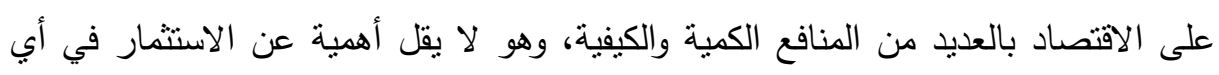

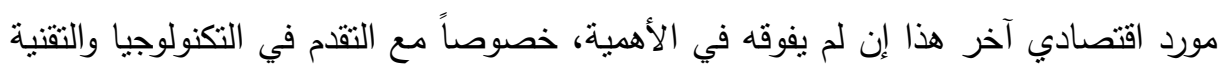

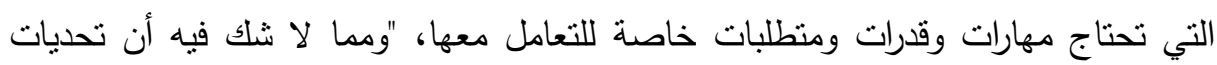

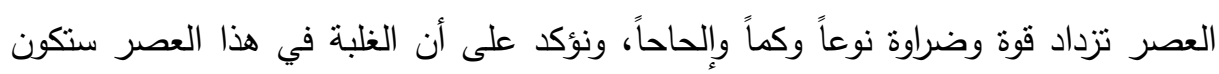

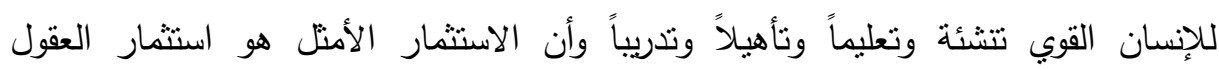

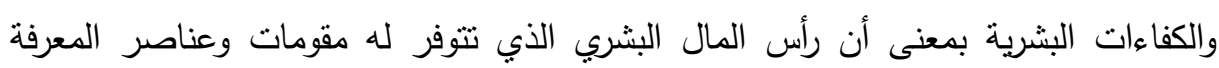

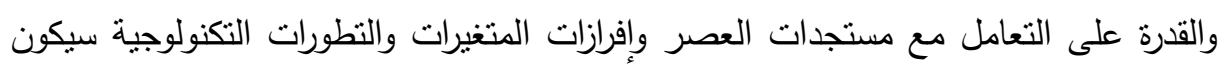
محكوماً عليه بالتخلف والتهميش والاستبعاد اقتصادياً وثقافياً".

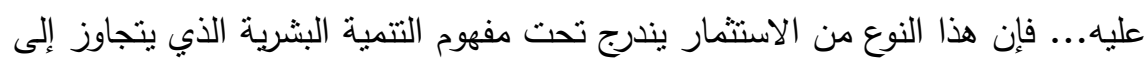

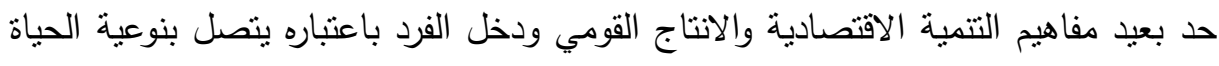
التي يعيشها الفرد، وقدرته على اكتساب المعرفة، وعلى الاستفادة من الموارد والخدمات التي لئي يحتاجها.

ولقد كثر استخدام مفهوم التتمية المستدامة على الساحة الدولية في الوقت الحاضر لكي

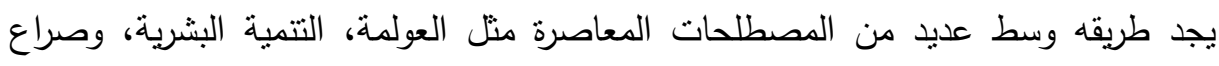

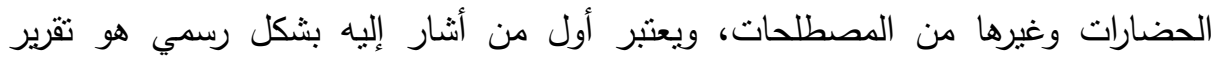

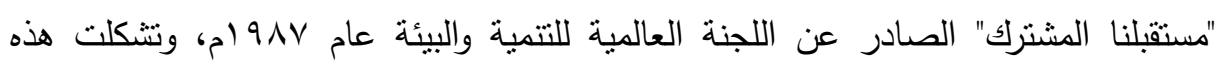

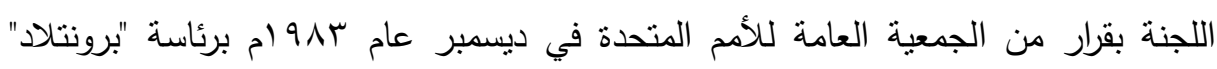

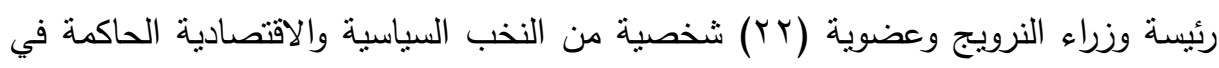
العامل، وذلك يهدف مواصلة النمو الاقتصادي العالمي دون الحاجة إلى إجراء تغييرات جذرية

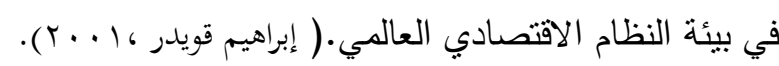

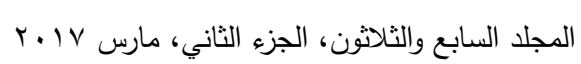




\section{مشفالة القراسلا}

من خلال الدراسات السابقة التي اطلع عليها الباحثّن دراسة (سالمة محمد سليمان عبد

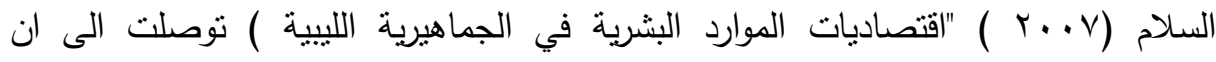
المجهودات المبذولة والمنجزات التي تمت في ليبيا خاصة في مجال الإنتاج والنهوض بالموارد البشرية وتتميتها لم تصل إلي المستوي المطلوب ولم تتجح حتى الآن في تحقيق النقلة النوعية

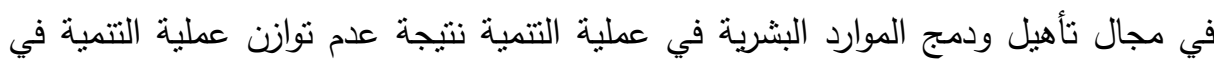
المجالات الاقتصادية والاجتماعية، حيت نتر الثقارير الى وجود الكثير من المشكلات التي تواجه قطاع التعليم والتدريب والبحث العلمي نحو تحقيق اهدافها . في ضوء ما سبق بتضح ان هناك فجوة كبيرة ما بين سياسات وبرامج التعليم والتدريب المهني واحتياجات سوق العمل، إضافة إلي عدم مواكبة برامج التأهيل والتدريب الحالية

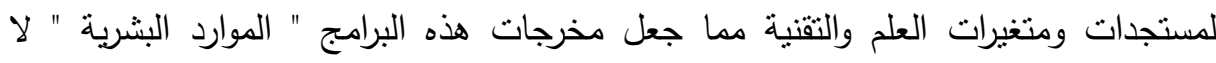
تواكب هي الأخري مستويات الإمكانيات الفكرية والعلمية والتتموية المتواصلة. ومن هنا يمكن بلورة مشكلة الدراسة في الإجابة عن التساؤلات التالية:

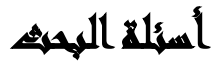

1-إلي أي مدي نجحت سياسات وخطط نتمية الموارد البشرية التي نفذت في ليبيا في الفترة

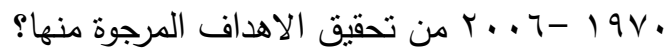

ז- ما مدى ارتقاء السياسات المتبعة في تتمية الموارد البشرية إلي المستوي الذي يحقق من الن الن

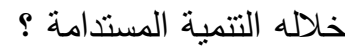
r-ما مدى توافق السياسات التعليمية المتبعة مع المنطلبات والتحديات التي تفرضها النطورات

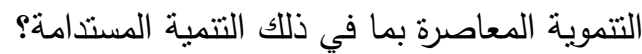




\section{أهمية القواسم}

تتبع اهمية هذا البحث من خلال عدة محاور اهمها : 1- اهمية اعداد وتخطيط ادراة برامج وسياسات تتمية الموارد البشرية في ليبيا والتي ينبغي ان

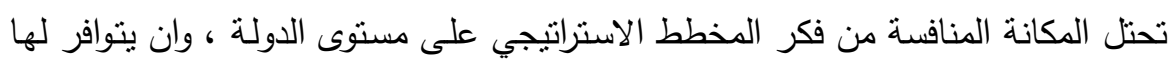

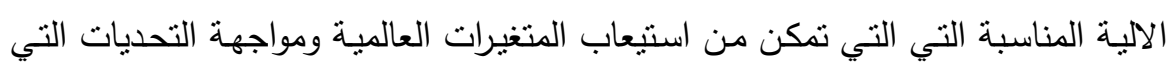
يفرضها العصر . بالبه ץ- الاستفادة العلمية والتطبيقية في مجالات التعليم والتدريب والبحث العلمي بقطاع التعليم في لئ ليبيا ، لاعداد نوعية من الموارد البشرية ذات قدرات ومهارات ابتكارية قادرة على مواجهة التحديات التتموية المعاصرة .

\section{أهساهث التوراسة}

1- الوقوف علي أهم النتائج والمكاسب التي تحققت في مجال تتمية الموارد البشرية في ليبيا

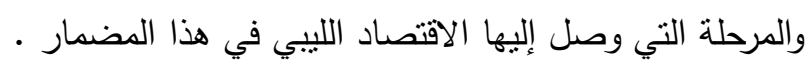

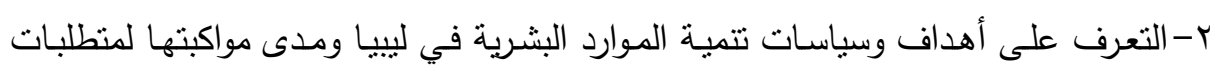
وتحديات التتمية المستدامة. r- إبراز السياسات التي تساعد على تجسيد التتمية المستدامة . ع - الوقوف على ايجابيات وسلبيات ومعوقات برامج وسياسات تتمية الموارد البشرية (التعليم _التدريب _ البحث العلمي ) في قطاع التعليم بليبيا في ضوء التطورات التتموية المعاصرة ه-تقديم مجموعة من المداخل والسياسات والبرامج العلمية لتنمية الموارد البشرية في قطاع التعليم تمكن القائمين على زيادة القدرة والكفاءة والفعالية لمواجهة منطلبات وتحديات التتمية

المستدامة وتحقيق أهدافها. 


\section{هزغياهي التوراسة}

تقوم هذه الدراسة علي الفرضيات التالية:

1- هنـاك درجـة ارتبـاط بين بنـاء خطط وبـرامج التعليم والتـدريب والبحث العلمي المواكبـة لكنطلبات التتمية وبين كفاءة سياسات إدارة الموارد البشرية بقطاع التعليم بليبيا في مواكبة

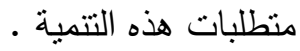
r- هنـاك درجـة ارتباط بين الاستثمارات الموجهة لخطط وبرامج التعليم والتدريب والبحث العلمي المواكبة لمنطلبات التتمية وبين كفاءة سياسات إدارة الموارد البشرية بقطاع التعليم بليبيا في مواكبة متطلبات هذه التتمية.

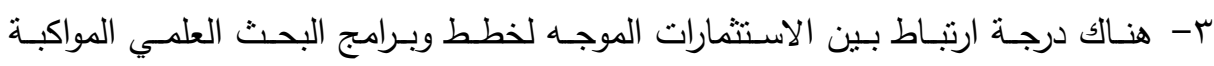
لمتطلبات التتمية وبين كفاءة سياسات إدارة الموارد البشرية بقطاع التعليم بليبيا في مواكبة البة البها منطلبات هذه التتمية. ع- هنالك علاقة ذات تأثثر معنوي بين إعادة صبياغة برامج وسياسـات إدارة وتتميـة الموارد

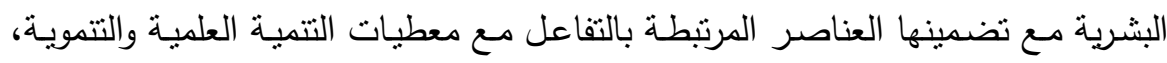
وبين زيادة قدرة قطاع التعليم على مواجهة التحديات الحالية والتعامل مع الفرص المستقبلية بلهية

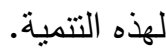

\section{منهمبر التصواسمة}

اتبـع الباحـث الأسـلوب الوصـفي في التحليـل عـن طريـق جمـع البيانـات والمعلومـات والإحصـائيات المتعلقة بموضوع الدراسـة سواء من الكتب أو التقارير والدوريات والموئتمرات العلمية وشبكة المعلومات الدولية وتبويبها علي هيئة جداول ومؤشرات ورسوم بيانية ومن ثم وصفها وتحليلها واستخلاص المعلومات منها .

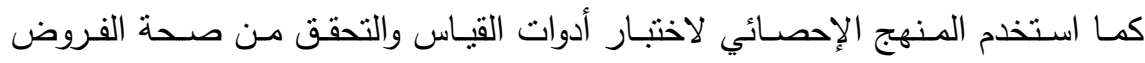
باستخدام الأساليب الإحصائية المناسبة، واستتباط النتائج من خلال تفسيرها 


\section{مورو التراسلة}

الحدود المكانية: تتمنل الحدود المكانية في دراسة الموارد البشرية في ليبيا.

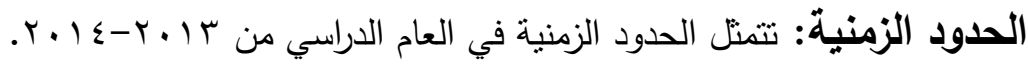

\section{هجتمع وكينيل الصراسلا}

يتمثل مجتمع الدراسـة في جميع العاملين الموجودين وقت اجراء الاستقصاء في قطاع

التعليم بيني وليد ليبيا، بمختلف المستويات التعليمية ( مؤهل جامعي فما فوق-مؤهل منتوسط التين

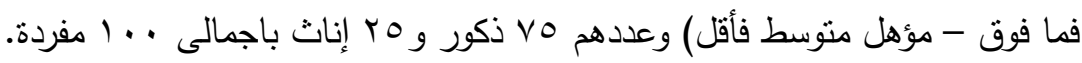

\section{القراسايت الماريها}

سـي الباحث - قدر الإمكان - إلي التعرف علي الجوانب المختلفة لموضـوع بحثه

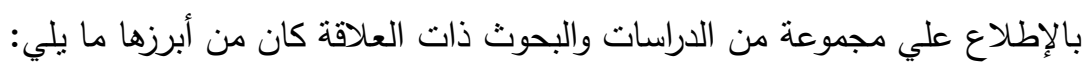

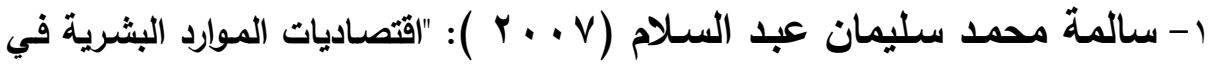

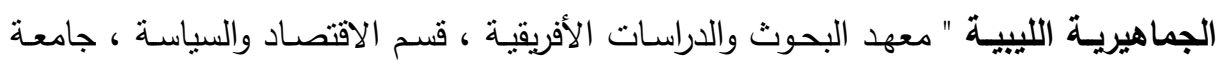
القاهرة ، جمهورية مصر العربية : تتاولت الباحثة بالوصف والتحليل أهم التطورات التي حدثت الته

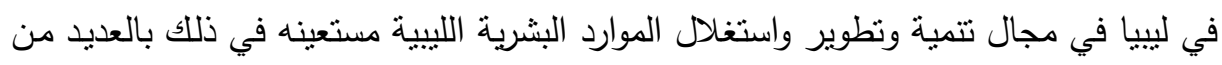
التقارير والإحصائيات والدراسات التي تتاولت هذا الموضوع والصادرة عن العديد من الجهات الرسمية في ليبيا كاللجنـة الثـعبية العامـة للقوي العاملـة والتدريب والتشتخيل واللجنـة الثـعبية العامة للتخطيط ، ومجلس التخطيط الوطني ( مجلس التخطيط العام ) سابقا وتوصلت الباحثة

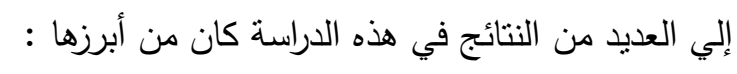
• علي الرغم من المجهودات المبذولة والمنجزات التي تمت في ليبيا خاصة في في مجال الإنتاج

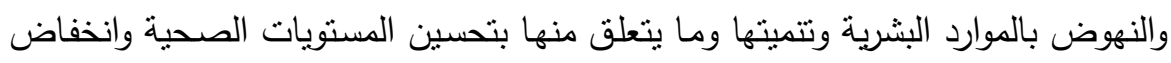

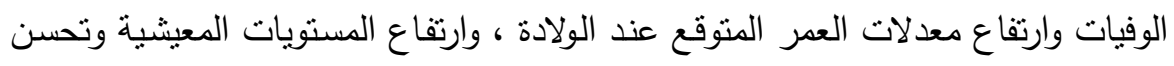

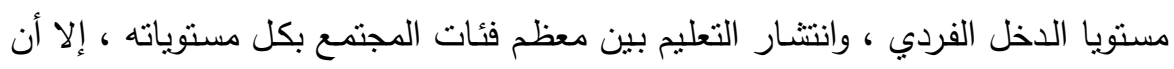

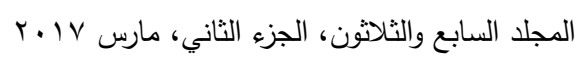


هذه الجهود لم تصل إلي المستوي المطلوب ولم تنجح حتى الآن في تحقيق النقلة النوعية

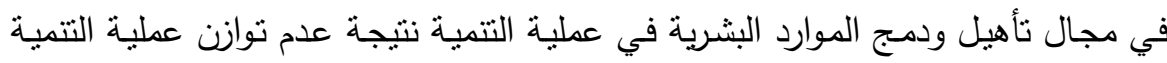
في المجلات الاقتصادية والاجتماعية .

• وجود فجوة كبيرة ما بين سياسات وبرامج التعليم والتدريب المهني واحتياجات سوق العمل ، مما زاد من نسب البطالة بجميع صورها وأنثكالها إضافة إلي عدم مواكبة برامج التأهيل

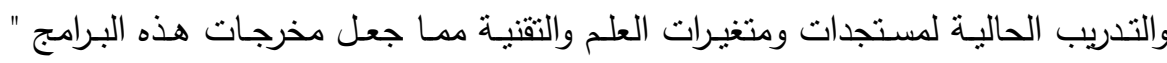

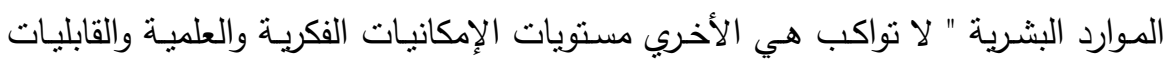

المعرفية المطلوبة في سوق العمل مما زاد من الاعتماد علي الكفاءات الأجنبية .

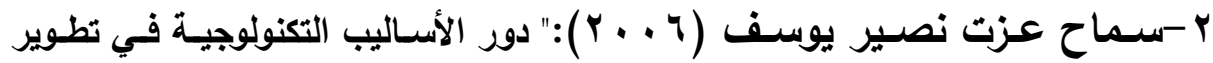
التنمية البشرية " كلية التجارة، جامعة عين شمس، جمهورية مصر العربية، قامت الباحثة بتقسيم هذه الدراسة إلي بابين رئيسيين وكانت فحوي كلا منهما علي النحو التالي: يتعرض الباب الأول إلي الإطار الفكري للتتمية البشرية حيث يتتاول فيه الباحثة دفهوم التتمية البشرية وقياسها وسياستها وأبعادها وكيفية نطور نظريات راس المال البشري. في حين تستعرض في الفصل الثاني علاقة مفهوم التتمية البشرية بالمفاهيم التتمويـة

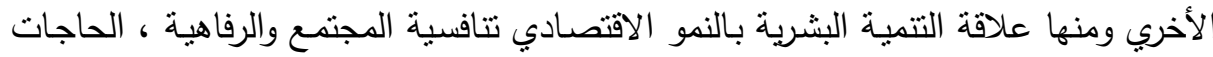

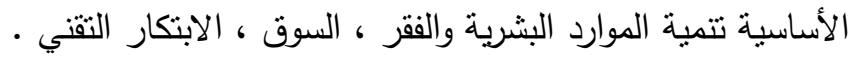

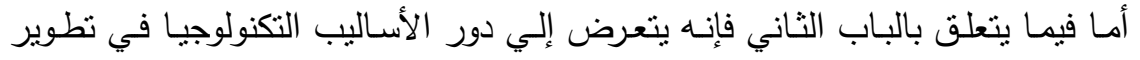

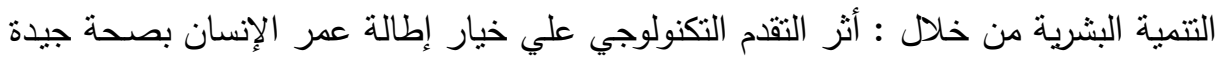
أثر التقام التكنولوجي علي زيادة القدرة العلمية والمعرفية لدي الإنسان وأثر الثقدم التكنولوجي التئي

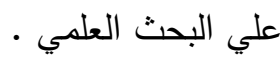
وكاتت أبرز النتائج التي توصلت إليها هذه الدراسة علي النحو التالي:

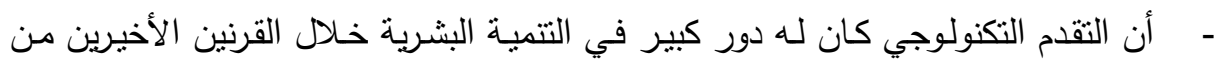
خلال مساهمته الفعالة في بداية الموجه الحديثة للنمو بعد توقف النمو السكاني في أوروبا 
منذ القرن الرابع عشر وحتى القرن الثامن عشر بسبب الأوبئة والأمراض من خلال إغناء

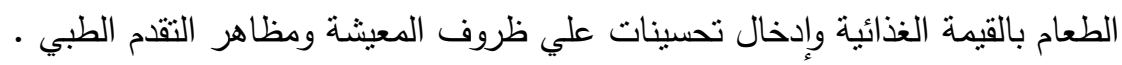

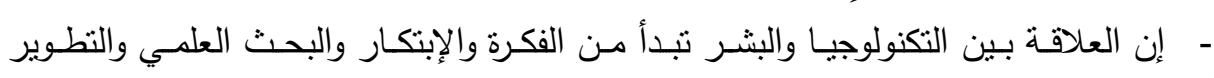

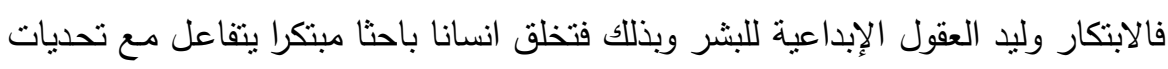

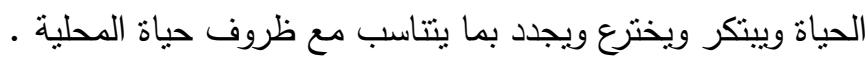

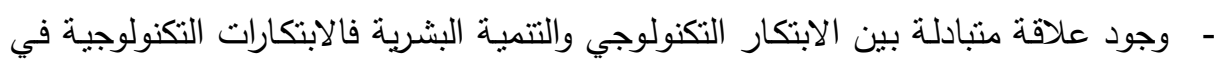
الزراعة والصناعة والطب أدت إلي القضاء علي الفقر وارتفاع مستويات التعليم واستخدام

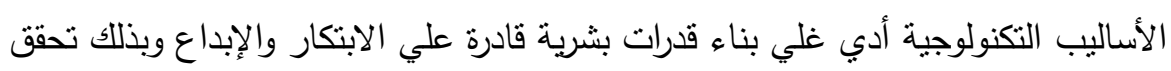

$$
\text { مستويات معيشة كريمة ونمو اقتصادي • }
$$

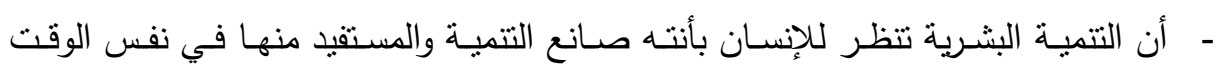

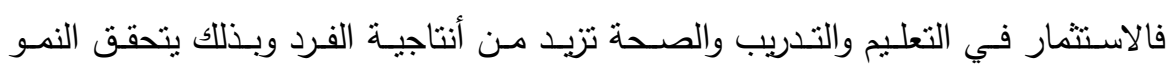

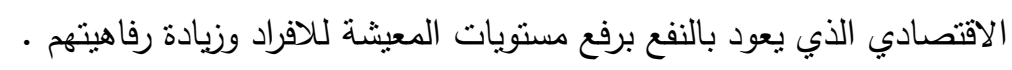

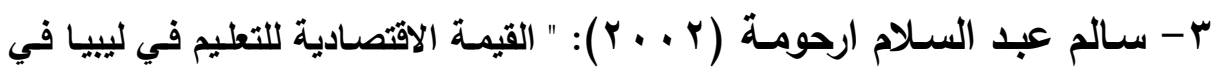
ضوء التنمية البشرية " قسم أصول التربية ، جامعة عين شمس ، جمهورية مصر العربية قام الباحث بتقبيم هذه الدراسة إلي خمسة فصول تناول فيها الموضوعات التالية:

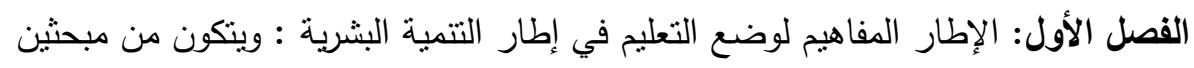

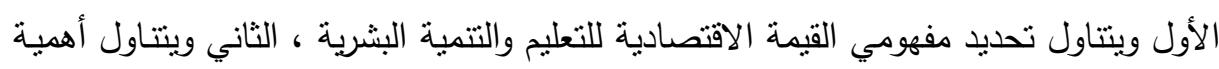

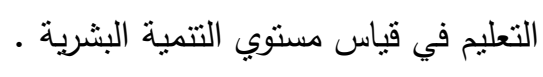

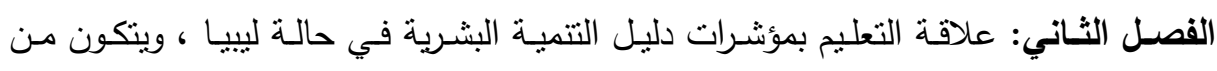

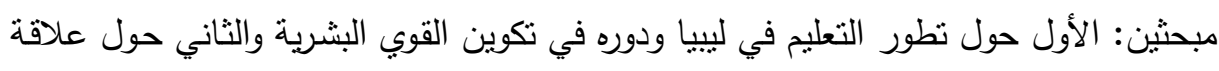

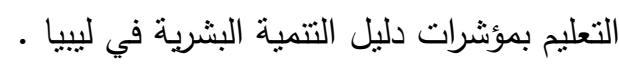
الفصل الثالث: الإنفاق علي التعليم في ليبيا ويتكون من مبحثين : الأول ويتتاول الإنفاق

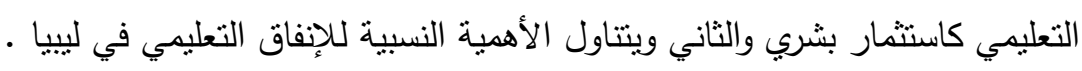

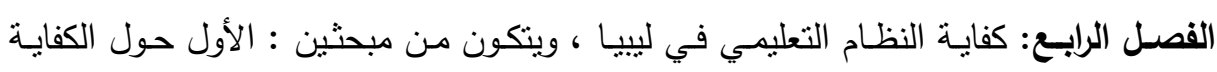
الداخلية والثاني حول الكفاية الخارجية

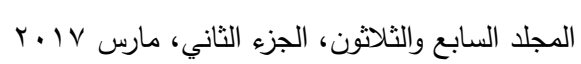


الفصل الخامس: ويتتاول مظاهر العائد الاقتصادي الاجتماعي للتعليم في ليبيا

$$
\text { وكانت أبرز نتائج هذه الدراسة ولنّان }
$$

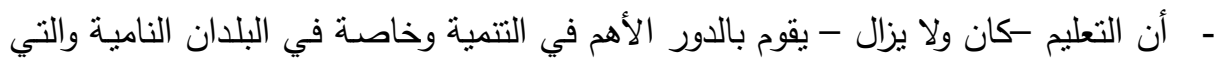

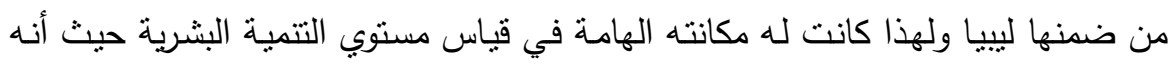

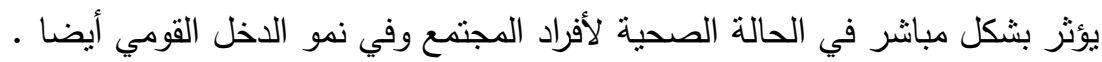

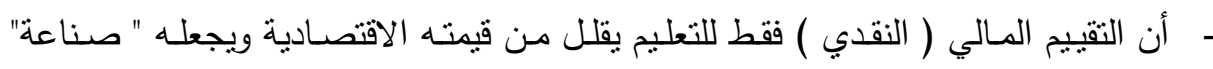

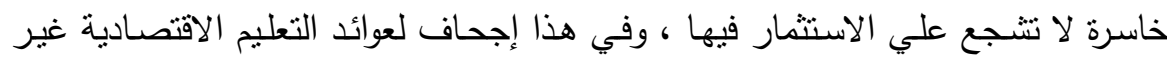

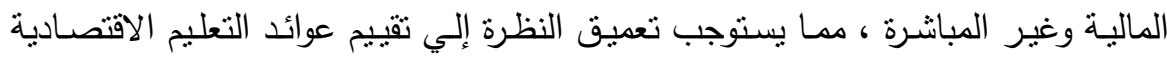

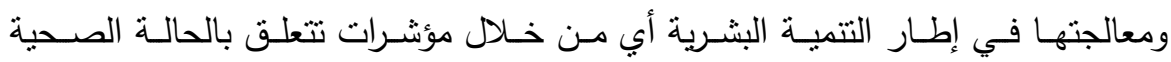
والتعليمية والاقتصادية لإفراد المجتمع.

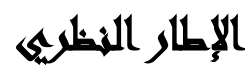

تطور ماهية التنمية البشريةة: تبلور مفهوم التتمية البشرية مع بداية التسعينيات من القرن العشرين، حيث تم تعريفه وتحديده في تقرير التتمية البشرية الأول الذي أصدره برنامج الأمم

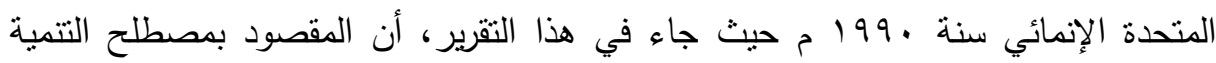
البشرية أنها : " عملية توسيع خيارات الناس - لا مجرد الخيارات ما بين أنواع مختلفة من هن هن

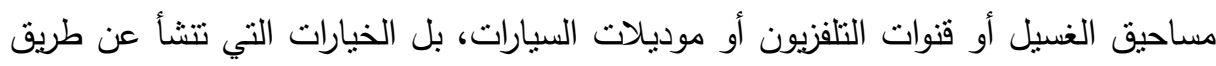
توسيع القدرات البشرية والطريقة التي يعمل بها البشر - أي ما يفعله الناس وما يمكن أن بلن يفعلوه في حياتهم. ماهية التنمية: جاء في تعريفات الأمم المتحدة أن التتمية هي: " عبارة عن مجموعة من الوسائل والطرق التي تستخدم بقصد توحيد جهود الأهالي مع السلطات العامة من أجل تحسين مستوى الحياة من النواحي الاقتصادية والاجتماعية والثقافية في المجتمعات القومية والمحلية،

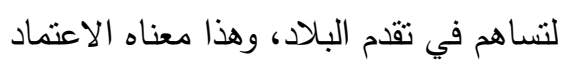


ماهية الموارد البشرية: تعرف الموارد البشرية بأنها حجم القوى العاملة لبلد ما، وتعتمد فعالية هذه الموارد على مستوى التعليم والتدريب لهذه القوى، فكلما ارتفع المستوى الفني للموارد

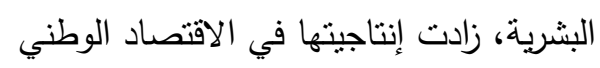

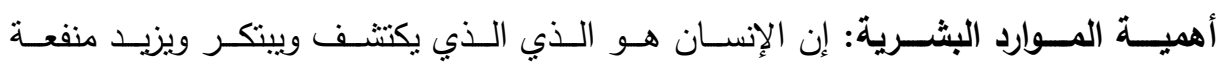

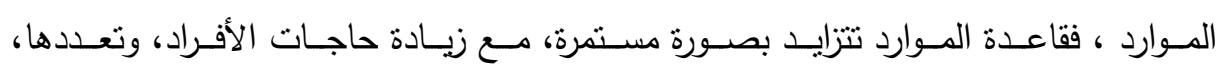

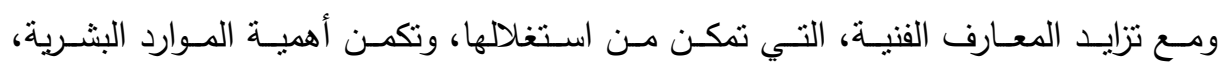

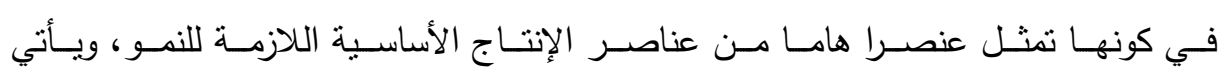

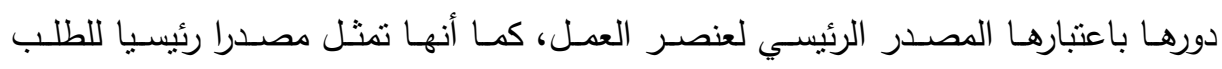

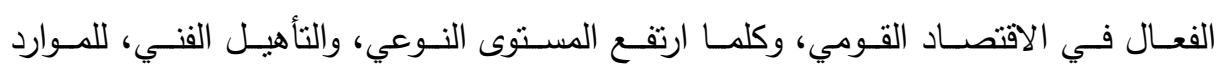

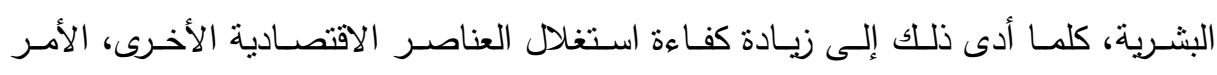
الذي يؤدي إلى زيادة القدرة الإنتاجية.

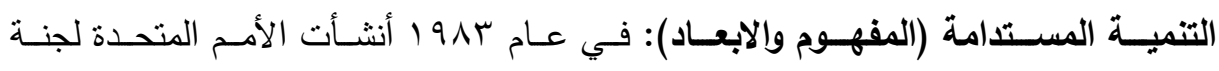

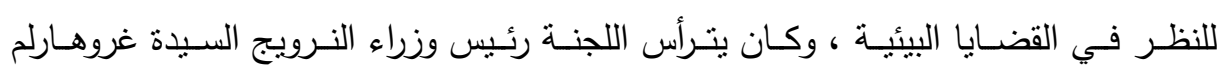

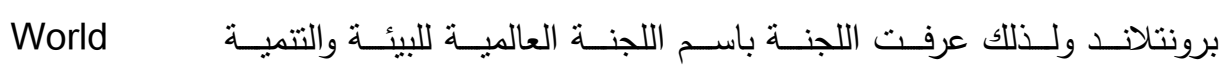
commission on Environment and Brundtland commission

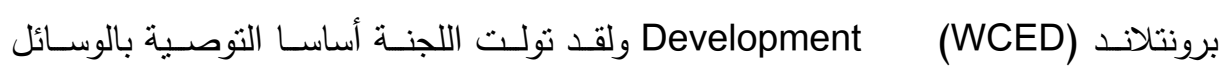

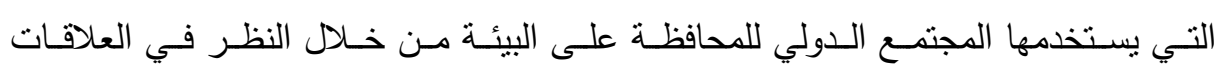
القائمة بين الأفراد والموارد، وبين البيئة والتتمية(1)

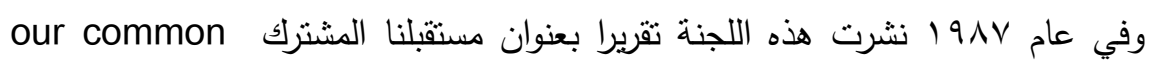
والذي يعرف باسم تقرير برونتلاند وكان هذا التقرير هو أول محاولة لجمع أفكار

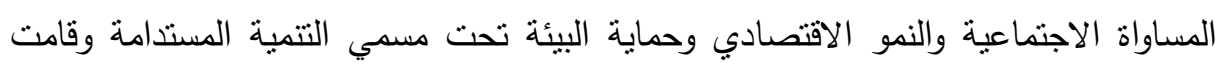
اللجنة بتعريف التتمية المستدامة بأنها:

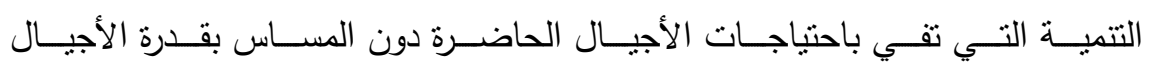
المقبلة على تلبية احتباجاتها. 
أبعاد التنمية المستدامة:

ا - البعـــ الاجتمــاعي: تتمثل القضـايا المرتبطـة بالأبعـاد الاجتماعيـة للتتميـة المسـتدامة

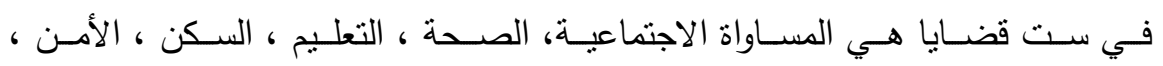
السكان.

r - البعـــ الاقتصــادي: ويتمثنل هـذا البعـد في شـكل مؤشـرات قضـايا البنيـة الاقتصـادية

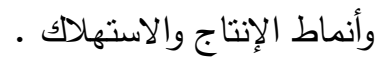
r-البعد البيئي: يرتبط الاهنمام بالبيئة بالدور الذي يمكن أن تلعبه الظروف البيئية المتدهورة

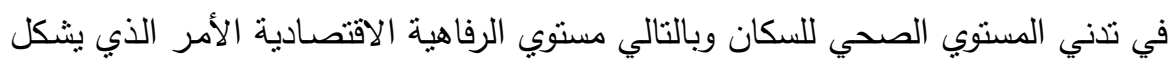
تحديا كبيرا في سبيل تحقيق التتمية المستدامة حيث تشير التقديرات التي جرت أخيرا إلي لهي

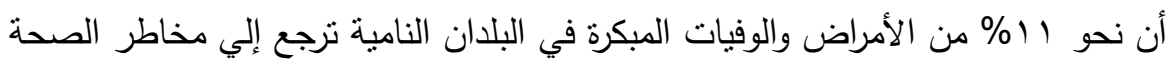

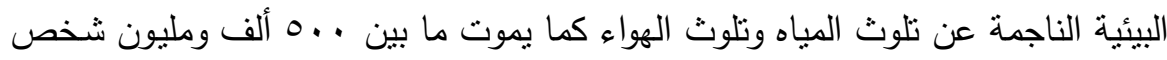

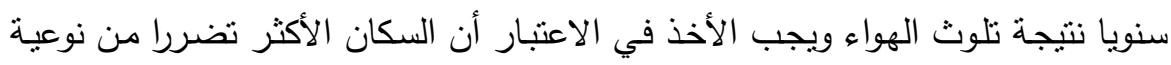

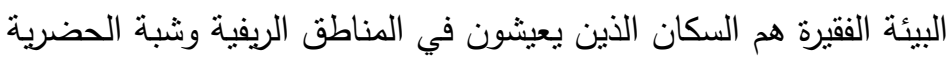
العلاقة بين التنمية البشرية والتنمية المستدامة: لقد أولت الأمم المتحدة كما أثرنا اهتمام التئية

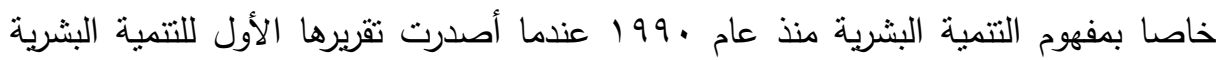
وطبقا لما ورد في التقارير المنتالية الصادرة عن البرنامج الإنمائي للامم المتحدة فقد عرفت التهات

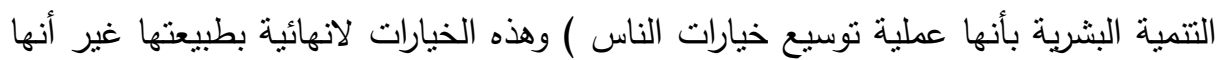
تتحدد من الناحية الواقعية بمحددات اقتصادية واجتماعية وثقافية وسياسية بالإضافة إلي ما يمكن أن يكون متاحا من سلع وخدمات ومعارف لتلبية هذه الاحتياجات التي يمتد مجالها من الحاجات إلي الطعام والثراب والمسكن والصحة والبيئة النظيفة الخ ،إلي الرغبة في المشاركة في كل ما يجري في المجتمع ومن ناحيتها تتطلع التتمية المستدامة إلي أن تصبح عملية التتمية مستمرة ومن شواغلها أن التتمية الجارية الآن ، ستصطدم بنقص الموارد نتيجة

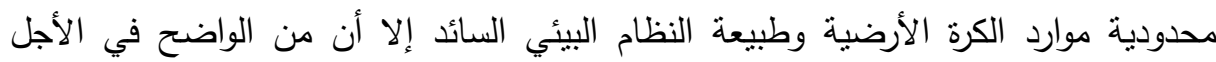

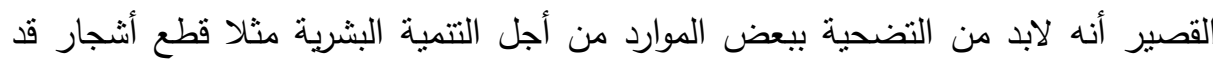


تتعدم فرص نموها مجددا لتوفير الوقود للفقراء من الناس وفي نفس الوقت فإنه لا سبيل إلي

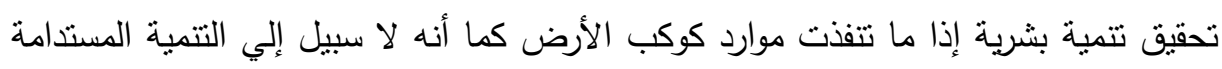

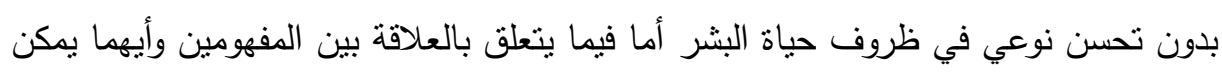

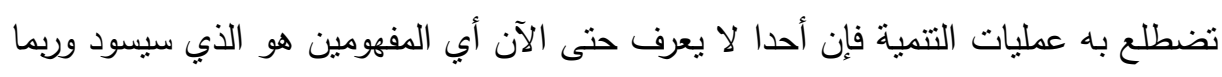

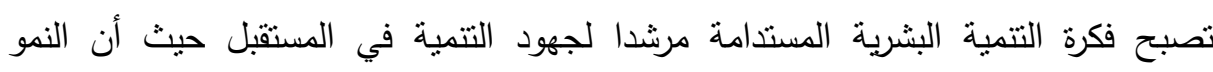
الاقتصادي شرط ضروري ولكنه ليس كافيا لوضع استراتيجية للتنمية البشرية.

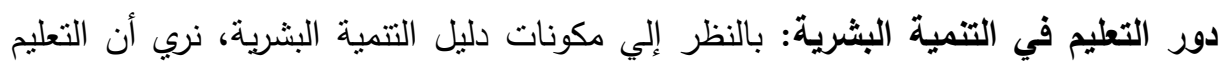

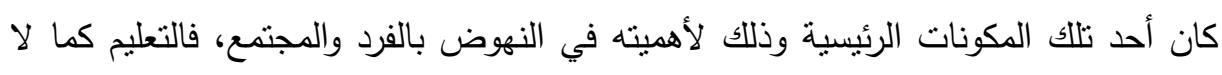

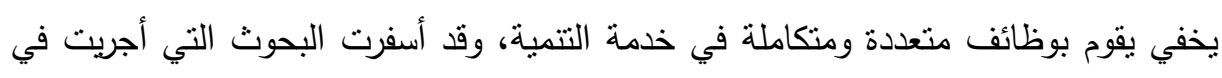

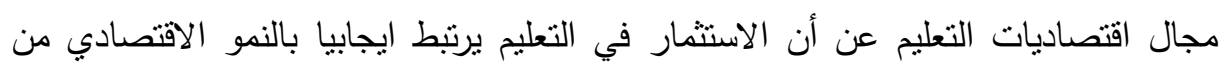

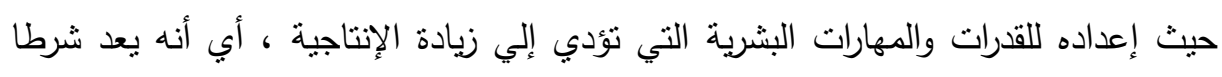

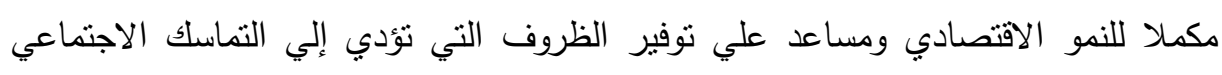

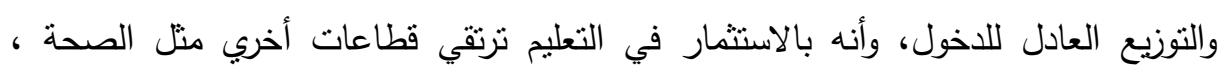

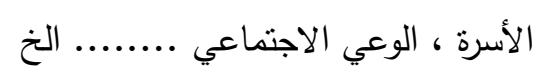

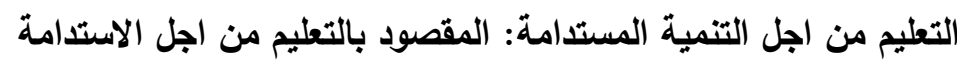

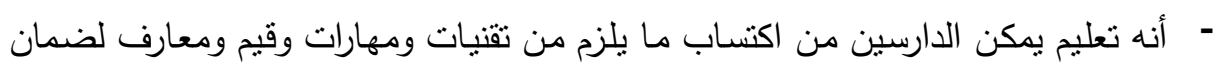
تتمية مستدامة

- تعليم يتيسر للجميع الانتفاع بمختلف مستوياته أيا كان السياق الاجنماعي (البيئة العائلية

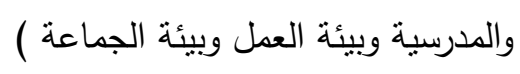

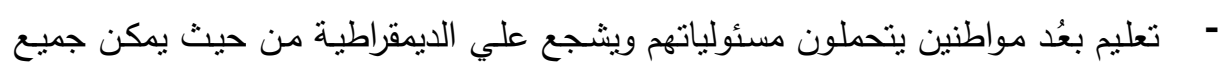

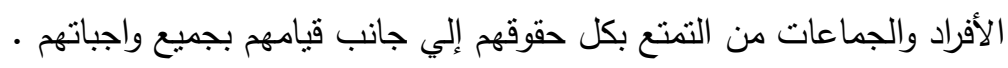
- تعليم يدخل في منظوره التعلم مدي الحياة .

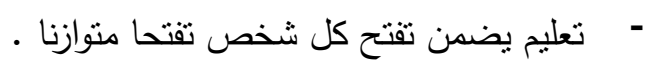




\section{إجراءايه التراسمة}

عينة الاراسة: لقد قام الباحث بتوزيع (•ـ ( ) استمارة على مفردات مجتمع الدراسة، وقد بلغ

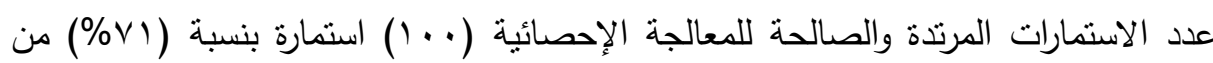
حجم العينة.

ويوضح الجدول الآتي رقم (1) بيان بعينة المبحوثين الذين استوفوا قوائم الاستقصاء

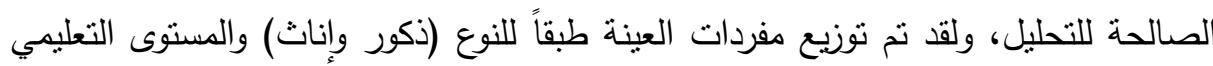

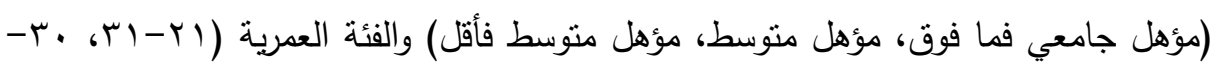

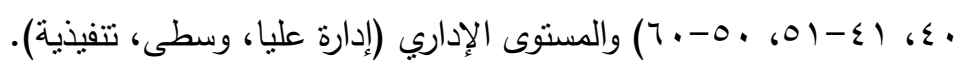
واعتمدت الباحثة في صدق المقياس على:

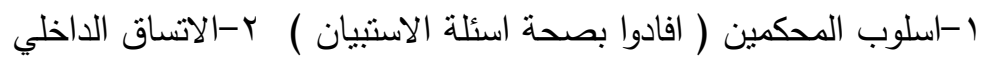

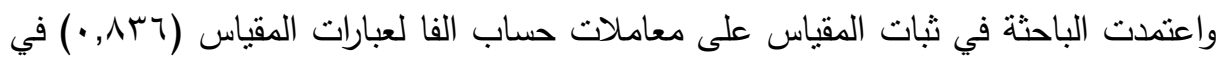

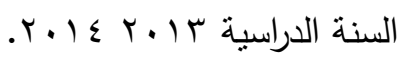
ويتكون هذا الاستبيان من مداخل رئيسية تتمثل في: 1- انتشار التعليم والتدريب والبحث العلمي المواكب لنتمية. r- توجيه مزيد من الاستثمارات نحو نشر التعليم والتدريب والبحث العلمي.

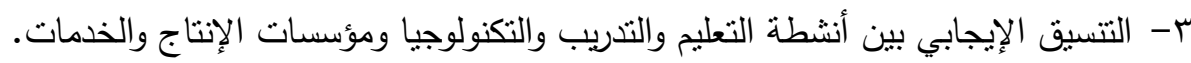

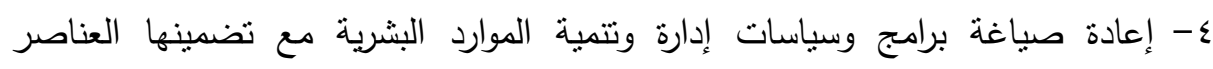

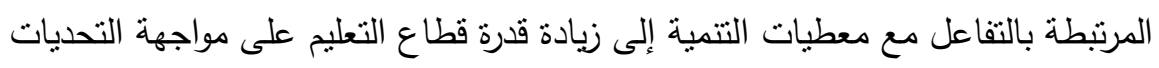
الحالية والتعامل مع الفرص المستقبلية. وتشمل هذه المداخل على مجموعة من الأسئلة يحتوي كل منها على مجموعة من العبارات تمثل النقاط الرئيسة للبحث الميداني. 
أحمد فؤاد مندور وآخرون

جدول رقم(1): توزيع مفردات العينة الصالحة للتحليل طبقاً للمتغيرات الديموغرافية

\begin{tabular}{|c|c|c|c|c|c|c|c|c|c|c|}
\hline إلعينة & $\begin{array}{c}-01 \\
7 .\end{array}$ & $\begin{array}{c}-\leqslant 1 \\
0 .\end{array}$ & $\begin{array}{c}-r_{1} \\
\varepsilon .\end{array}$ & $\begin{array}{c}-r_{1} \\
r .\end{array}$ & فَأقلَ & المتوسط & فمالى & إناث & ذكور & بيان \\
\hline IT & 0 & 0 & r & - & - & $r$ & 1. & r & 1. & الإدارة \\
\hline 0 . & 17 & Ir & Ir & 1. & 0 & $r$. & ro & $r$. & ro & الإدارة \\
\hline rᄉ & 0 & 1. & 1. & $1 \pi$ & rᄉ & - & - & $r$ & r. & الإلتفدارة \\
\hline $1 \ldots$ & rT & $r V$ & $r \leqslant$ & rT & $\varepsilon r$ & Tr & ro & ro & vo & الجمينة العـالى \\
\hline
\end{tabular}

ويوضح الجدول رقم (1) بيان بعينة المبحوثين ، ولقد تم توزيع مفردات العينة طبقا للنوع

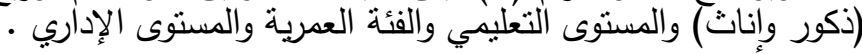

عرض النتائج المتعلقة بفروض والمنئ الإراسة:

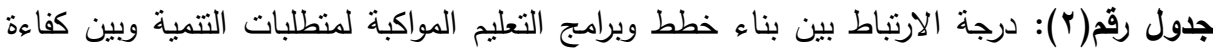

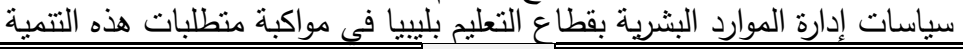

\begin{tabular}{|c|c|c|c|c|c|c|}
\hline \multirow{2}{*}{\multicolumn{2}{|c|}{ معامل الارتباط }} & \multicolumn{2}{|c|}{ اختبار T } & التتانغير & \multirow{2}{*}{ المتغير المستقل } & \multirow[b]{2}{*}{ p } \\
\hline & & المعنتوية & القيمة & \multirow{9}{*}{ 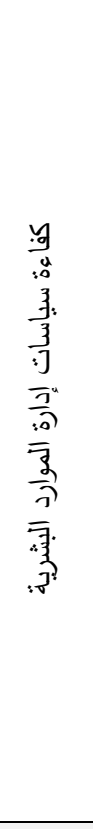 } & & \\
\hline & & $\cdot, \cdots$ & $r, \leqslant 0$ & & 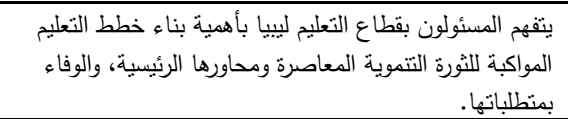 & 1 \\
\hline & & $\cdot, \cdots 7$ & $r, \wedge)$ & & يتتم بناء استراتيجية التعليم بليييا في ضوء منطلبات التتمية & $r$ \\
\hline & & $\cdot, \cdots v$ & $r, 11$ & & التتتموية خطط وبرامجر التعليم بليييا بالوفاء بمنطلبات التتمية & $r$ \\
\hline & & $\cdot, \cdots$ & $1, \wedge 1$ & & 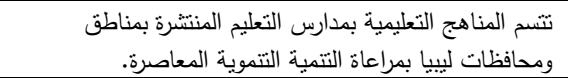 & $\varepsilon$ \\
\hline & & $\cdot, \cdots V$ & $r, \cdot 1$ & & يتتم تتفيذ الخطط والبرامج التعليمية بليبيا وفق الأساليب العلمية & 0 \\
\hline & & $\cdot, \cdots$ & 1,99 & & ويتم تقلتيبم النططط والبرامج والمناهج التعليمية بليييا وفق محاور & 7 \\
\hline & & $\cdot, \cdots$ & r,vo & & يتم تطوير الخطط والبرامج والمناهج التعليمية ليبيا وفق & $v$ \\
\hline \multicolumn{2}{|c|}{$\cdot, 77$} & $\cdot, \cdots 9$ & $r, 11$ & & 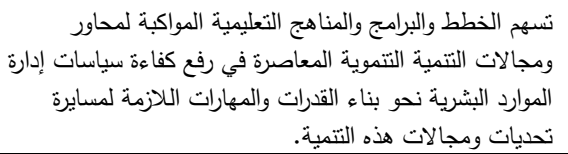 & $\wedge$ \\
\hline$\cdot, \ldots$ & $\cdot, T V$ & \multicolumn{5}{|c|}{ الإجمالي } \\
\hline
\end{tabular}

"درجة الثقة (99, • )

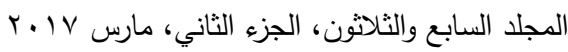

295 
جدول رقم(؟): درجة الارتباط بين بناء خطط وبرامج التدريب المواكبة لمنطلبات التتمية وبين كفاءة سياسات إدارة الموارد البشرية بقطاع التعليم ليبيا في مواكبة متطلبات

هذه التتمبة.

\begin{tabular}{|c|c|c|c|c|c|}
\hline 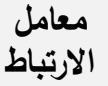 & \multicolumn{2}{|c|}{ اختبار T } & \multirow{2}{*}{ الت التغير } & \multirow{2}{*}{ المتغير المستقل } & \multirow{2}{*}{ p } \\
\hline القيمة & 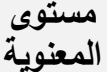 & القيمة & & & \\
\hline$\cdot,\rceil \wedge$ & $\bullet, \cdots$ & $\varepsilon, \cdot 1$ & \multirow{8}{*}{ 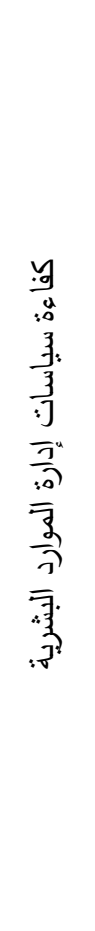 } & 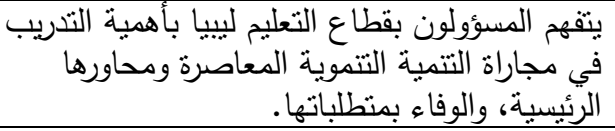 & 1 \\
\hline$\cdot, 09$ & $\cdot, \cdots$ & $Y, \wedge V$ & & 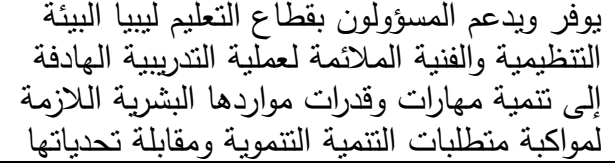 & $r$ \\
\hline$\cdot, 0 \wedge$ & $\cdot, \cdots)$ & $r, \wedge \Gamma$ & & 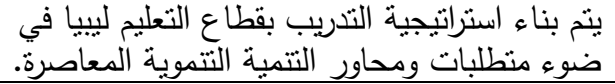 & $r$ \\
\hline$\cdot, 0 \leqslant$ & $\cdot, \cdots$ & $r, v$. & & بالوفاء بمنطلبات التتمية التتموية المعاصريب التعرة. لبييا & $\varepsilon$ \\
\hline$\cdot, 0$. & $\cdot, \cdot$ & $Y, O$. & & وفتم تحديد الأساليب العتياجية التتمويبية المتطورة. التطليم ليبيا & 0 \\
\hline$\cdot, \varepsilon 1$ & $\cdot, \cdots$ & 1,74 & & 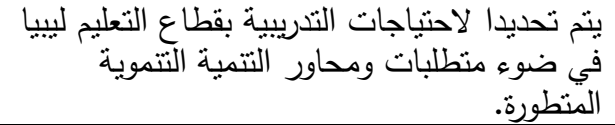 & 7 \\
\hline$\cdot, 0 \leqslant$ & $\cdot, \cdots 7$ & 1,79 & & 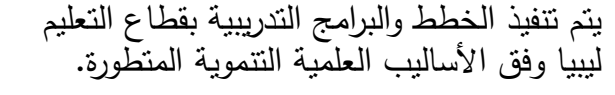 & V \\
\hline •,OY & $\cdot, \cdots q$ & $Y, T)$ & & 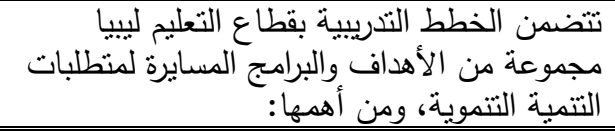 & $\wedge$ \\
\hline
\end{tabular}


جدول رقم(؛ ): درجة الارتباط بين بناء خطط وبرامج البحث العلمي المواكبة لمتطلبات التتمية وبين كفاءة سياسات إدارة الموارد البشرية بقطاع التعليم بليبيافي مواكبة

منطلبات هذه التتمية.

\begin{tabular}{|c|c|c|c|c|c|c|}
\hline \multirow{2}{*}{\multicolumn{2}{|c|}{ معامل الارتباط }} & \multicolumn{2}{|c|}{ اختبار T } & التابغير & \multirow{2}{*}{ المتغير المستقل } & \multirow{2}{*}{ ? } \\
\hline & & 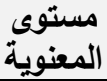 & القيمة & \multirow{12}{*}{ 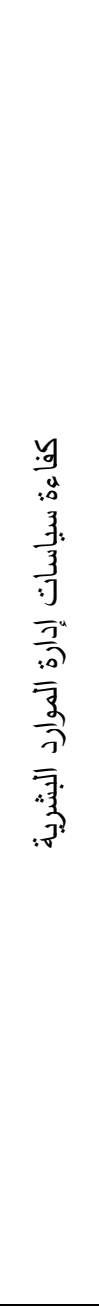 } & & \\
\hline \multicolumn{2}{|c|}{$\cdot, 09$} & $\cdot, \cdots$ & $r, 7$. & & 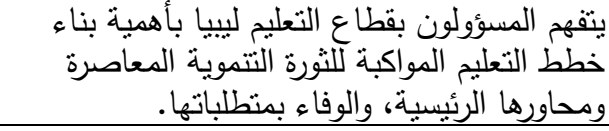 & 1 \\
\hline & & $\cdot, \cdots 1$ & $r, 00$ & & 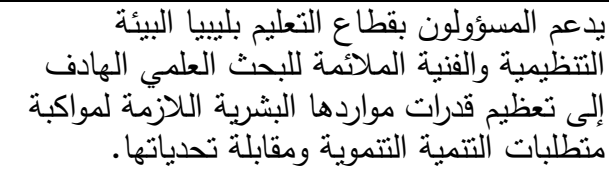 & r \\
\hline \multicolumn{2}{|c|}{$\cdot, 70$} & $\cdot, \cdots$ & سז, r & & يتملبات التتراتية التتموية البحث المعاصمي بليبيا في ضوة. & $r$ \\
\hline \multicolumn{2}{|c|}{$\cdot, 0 \wedge$} & $\cdot, \cdots 1$ & $Y, O V$ & & التتمية التتموية وبرامج التعليم بليييا بالوفاء بمنطلبات & $\varepsilon$ \\
\hline \multicolumn{2}{|c|}{$\cdot, O Y$} & $\cdot, \cdots r$ & $Y, Y Y$ & & 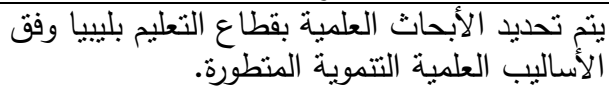 & 0 \\
\hline \multicolumn{2}{|c|}{$\cdot, \leqslant 7$} & $\cdot, \cdots 9$ & 1,91 & & 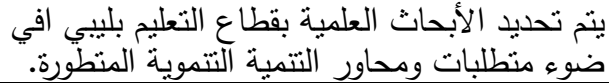 & 7 \\
\hline \multicolumn{2}{|c|}{$\cdot, \varepsilon$. } & $\cdot, \cdots$ & $1,7 \varepsilon$ & & لبتم تتفيذ الأبحاث العلمية التقطية المتطوة التعليم بليبيا وفق & $V$ \\
\hline \multicolumn{2}{|c|}{$\cdot, \varepsilon 1$} & $\cdot, \cdots$ & $1, V$. & & يتابلة تقييم الأبحاث التنمية التنموبة بقطاع التعليم بليبيا وفق & $\wedge$ \\
\hline \multicolumn{2}{|c|}{$\cdot, \cdot \times 1$} & $\cdot$ & $\varepsilon, \cdot r$ & & وفتم المستجدات الأبحاث العلمية المنطورة التعليم بليبيا & 9 \\
\hline \multicolumn{2}{|c|}{$\cdot, \varepsilon \Gamma$} & $\cdot$, & $1, \wedge$. & & 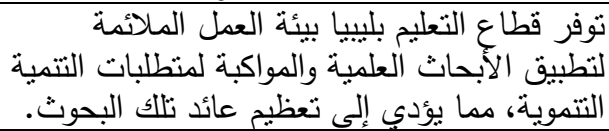 & 1. \\
\hline \multicolumn{2}{|c|}{$\cdot, 7 \varepsilon$} & $\cdot, \cdots \varepsilon$ & $r, 0$. & & 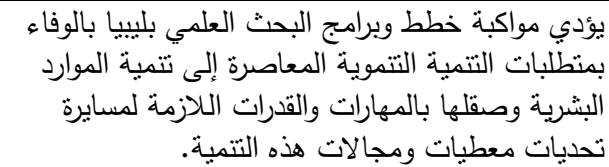 & 11 \\
\hline$\cdot, \cdots$ & דוד, & & & & الإجمالي & \\
\hline
\end{tabular}


جدول رقم(ه): درجة الارتباط بين الاستنمارات الموجهة لخطط وبرامج التعليم المواكبة لمتطلبات التتمية وبين كفاءة سياسات إدارة الموارد البشرية بقطاع التعليم

بليبيافي مواكبة متطلبات هذه التتمية.

\begin{tabular}{|c|c|c|c|c|c|c|}
\hline \multirow{2}{*}{\multicolumn{2}{|c|}{ الارتباط }} & \multicolumn{2}{|c|}{ اختبار T } & \multirow{2}{*}{ 哥牙 } & \multirow{2}{*}{ المتغير المستقل } & \multirow{2}{*}{ p } \\
\hline & & المعنتوية & القيمة & & & \\
\hline \multicolumn{2}{|c|}{$\cdot, 01$} & $\cdot, \cdots 1$ & $r, 10$ & \multirow{8}{*}{ الإدارة الماءة } & 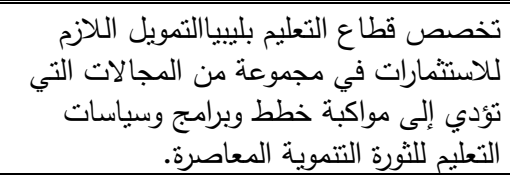 & 1 \\
\hline \multicolumn{2}{|c|}{$\cdot, T V$} & $\cdot, \cdots$ & $r, v)$ & & 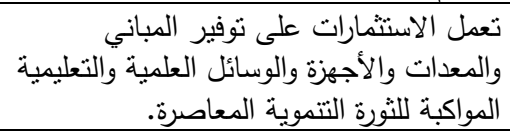 & $r$ \\
\hline \multicolumn{2}{|c|}{$\cdot, 01$} & $\cdot, \cdots r$ & $r, 1 T$ & & الععل الاستتمارات التعليمية المواكبة للثورة التتموية المعامل والورش & $r$ \\
\hline \multicolumn{2}{|c|}{ •, } & $\cdot, \cdots$ & $1,0 r$ & & 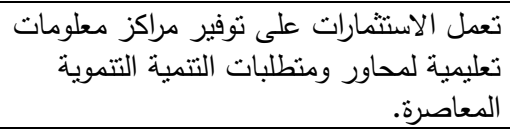 & $\varepsilon$ \\
\hline \multicolumn{2}{|c|}{ rT, • } & $\cdot, \cdots$ & r,70 & & 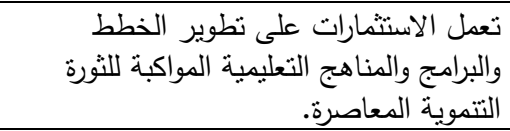 & 0 \\
\hline \multicolumn{2}{|c|}{., $0 \leqslant$} & $\cdot, \cdots r$ & $r, \ldots$ & & 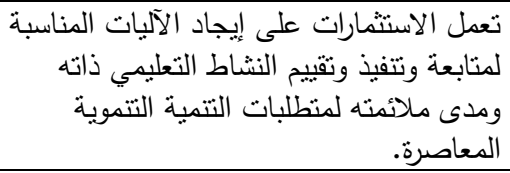 & 7 \\
\hline \multicolumn{2}{|c|}{$\cdot, \leqslant 1$} & $\cdot, \cdots$ & $1,9$. & & 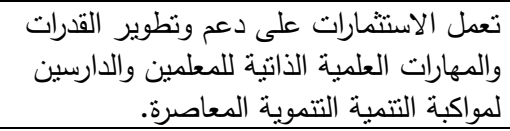 & V \\
\hline \multicolumn{2}{|c|}{., $0 \mathrm{~V}$} & $\cdot, \ldots$ & $r, \cdot q$ & & 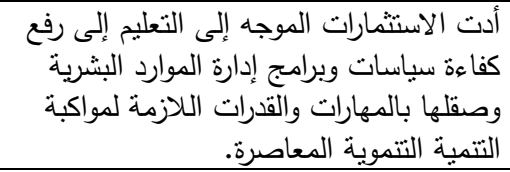 & $\wedge$ \\
\hline & $\cdot, 70$ & \multicolumn{5}{|c|}{ الإجمالي } \\
\hline
\end{tabular}

"درجة النقة (9, ·) 
جدول رقم(7): درجة الارتباط بين بناء خطط وبرامج التدريب المواكبة لمتطلبات التنمية وبين كفاءة سياسات إدارة الموارد البشرية بقطاع التعاليم بليبيافي مواكبة متطلبات

هذه التتمية.

\begin{tabular}{|c|c|c|c|c|c|}
\hline معامل الارتباط & \multicolumn{2}{|c|}{ اختبار T } & التابعير & \multirow{2}{*}{ المتغير المستقل } & \multirow{2}{*}{ ? } \\
\hline القيمة & مستوي & القيمة & \multirow{8}{*}{ 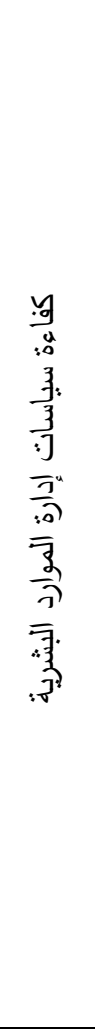 } & & \\
\hline • & $\cdot, \cdots V$ & $r, \lambda)$ & & 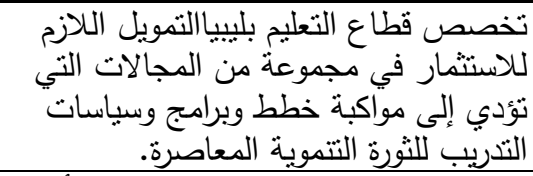 & 1 \\
\hline חזד, • & $\cdot, \cdots$ & $r, \cdot 1$ & & 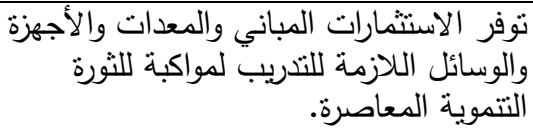 & $r$ \\
\hline$\cdot, 00$ & $\cdot, \cdots l$ & $r, \varepsilon \varepsilon$ & & التوفير الاستثمارات المعامل والورش والبيئة & $r$ \\
\hline • & $\cdot, \cdots$ & $r, \ldots$ & & 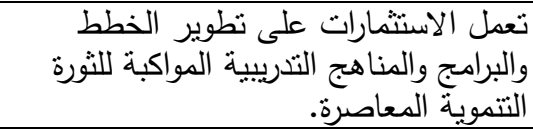 & $\varepsilon$ \\
\hline$\cdot, \leqslant 1$ & $\cdot, \cdots$ & 1,10 & & 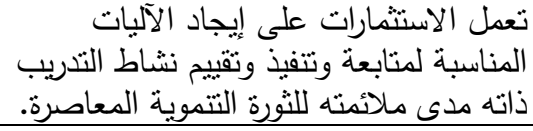 & 0 \\
\hline$\cdot, \varepsilon$. & $\cdot, \cdots$ & $1, \lambda 1$ & & 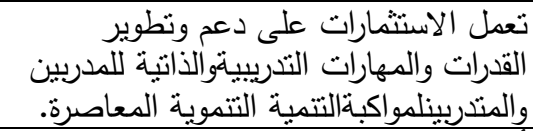 & 7 \\
\hline$\cdot, 01$ & $\cdot, \cdots 7$ & $r, T$. & & 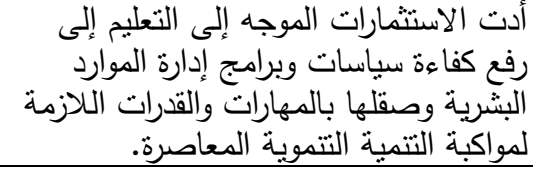 & V \\
\hline$\bullet, \ldots$ & & & & الإجمالي & \\
\hline
\end{tabular}

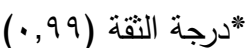


مجلة العلوم البيئية

معهز الدراسات والبحوث البيئية - جامعة عين شمس لهن

جدول رقم(V): درجة الارتباط بين بناء خطط وبرامج البحث العلمي المواكبة لمنطلبات التتمية

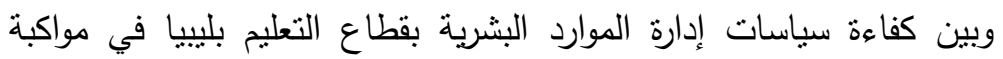

منطلبات هذه التتمية

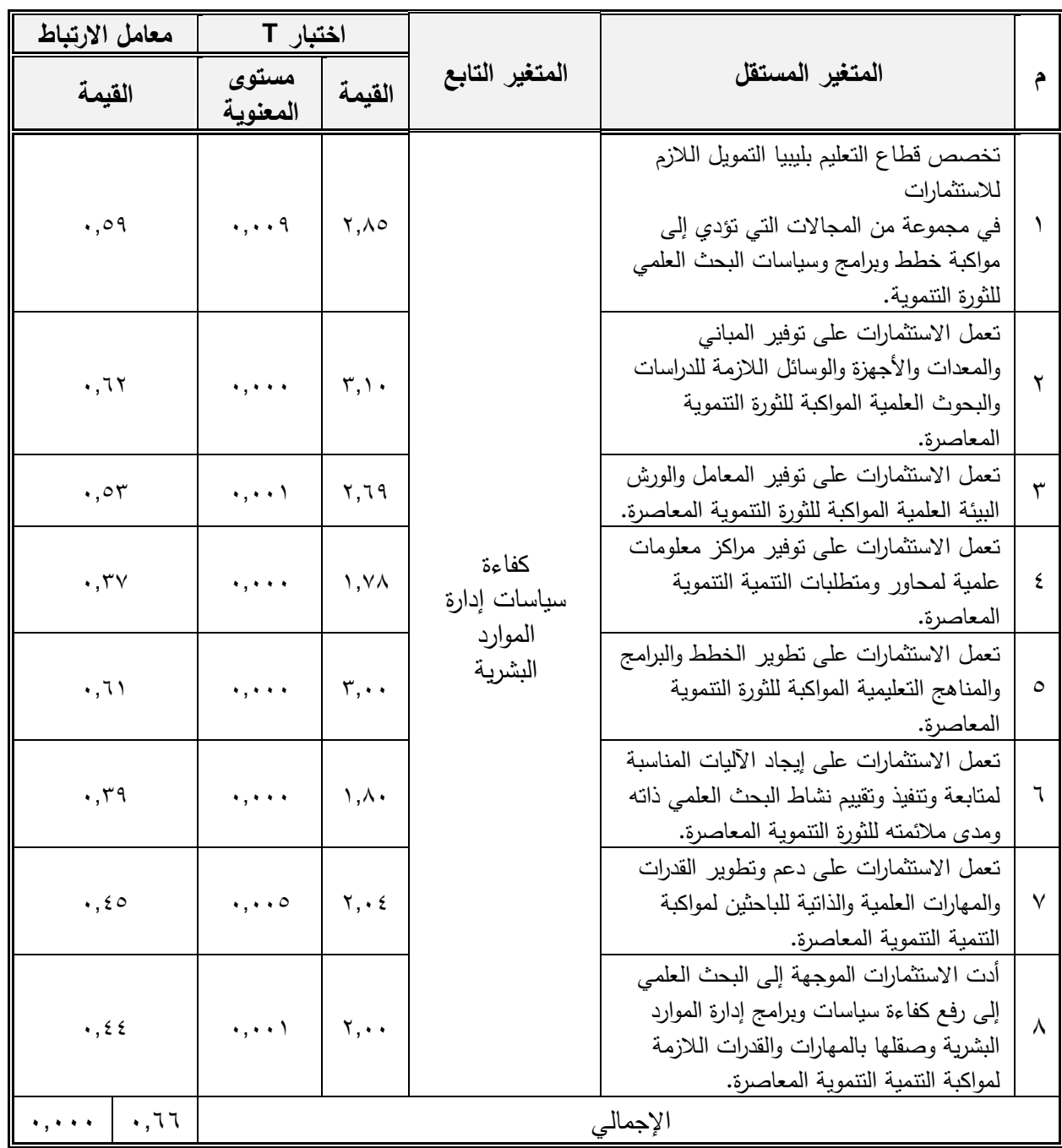

*درجة الثقة (99, · ) 
جدول رقم(^): درجة الارتباط بين تتسيق خطط وبرامج التعليم والتدريب والبحث العلمي المواكبة لمنطلبات التتمية والقطاعات الإنتاجية والخدمية، وبين كفاءة سياسات إدارة الموارد البشرية بقطاع التعليم بليبيا في مواكبة متطلبات هذه التتمية.

\begin{tabular}{|c|c|c|c|c|c|}
\hline معامل الارتباط & \multicolumn{2}{|c|}{ اختبار T } & التانغير & \multirow{2}{*}{ المتغير المستقل } & \multirow{2}{*}{ ? } \\
\hline القيمة & المعنوية - مستوي & 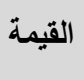 & \multirow{11}{*}{ 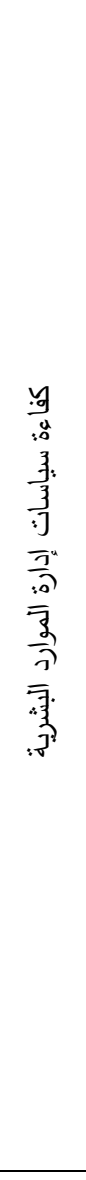 } & & \\
\hline$\cdot, \Gamma \varepsilon$ & $\cdot, \cdots$ & 1,9 & & هناك تتسيق بين خطط التعليم والتدريب والبحثي & 1 \\
\hline$\cdot, 7$. & $\cdot, \cdots$ & $r, .$. & & تتوفر سياسات علمية وتتمية واضحة وشاملة & r \\
\hline$\cdot, \varepsilon \cdot$ & $\cdot, \cdots 1$ & $r, \cdot r$ & & 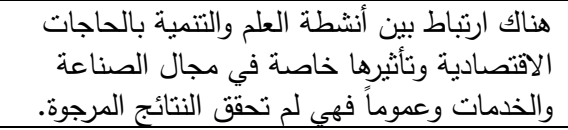 & $r$ \\
\hline$\cdot, \varepsilon$. & $\cdot, \cdots$ & $r \cdot, l$ & & 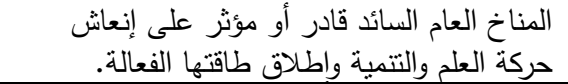 & $\varepsilon$ \\
\hline$\cdot, r$ & $\cdot, \cdots$ & $1, V V$ & & 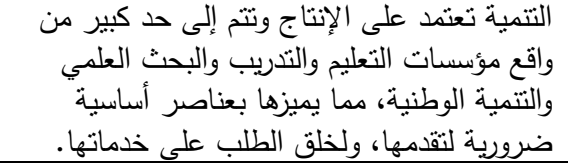 & 0 \\
\hline$\cdot$, ro & $\cdot, \cdots$ & 1,97 & & 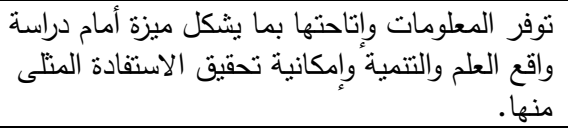 & 7 \\
\hline$\cdot, \Sigma \cdot$ & $\cdot, \cdots 7$ & $r, \cdots$ & & 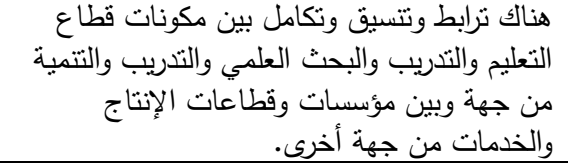 & $V$ \\
\hline$\cdot, 09$ & $\cdot, \cdots$ & r,qr & & تعظيم الفائدة من العلاقات والاتفاقات الدولية. & $\wedge$ \\
\hline$\cdot, 07$ & $\cdot, \cdots V$ & r,Ar & & المتقدم. وجود الفجوة بين المجتمع الليبي وبين العالم & 9 \\
\hline$\cdot, 01$ & $\cdot, \cdots 7$ & $r, 1 \cdot$ & & 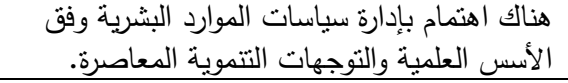 & 1. \\
\hline$\cdot, \cdots \cdot \mid, r \leq$ & & & & الإجمالي & \\
\hline
\end{tabular}

*درجة الثقة (99, •) 
جدول رقم(9): درجة نأثير إعادة صياغة برامج وسياسات إدارة الموارد البشرية مع تضمينها

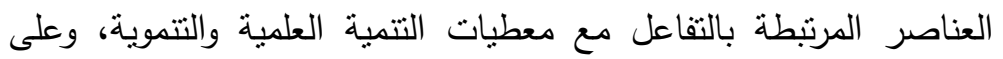

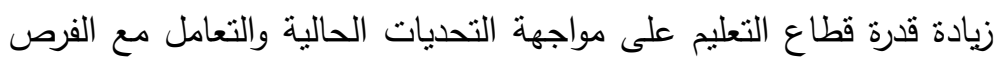
المستقبلية لهذه التتمية.

\begin{tabular}{|c|c|c|c|c|c|}
\hline المعنوية & $\begin{array}{l}\text { قيمة } \\
\text { (T) }\end{array}$ & المعياري & $\begin{array}{l}\text { الانحدار } \\
\beta\end{array}$ & المتغير & \\
\hline$\cdot, \cdots$ & $\varepsilon,|Y|$ & $\cdot, \cdot V r$ & $\cdot, 101$ & 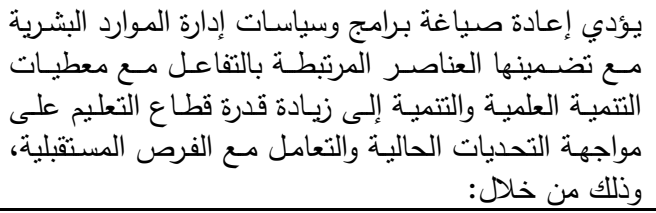 & 1 \\
\hline$\cdot, \cdots$ & $7, \Gamma \wedge q$ & $\cdot, \cdot \leq r$ & • & 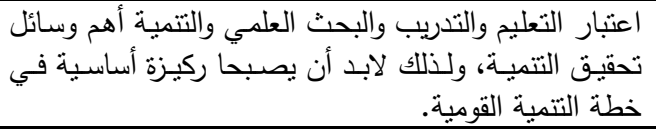 & r \\
\hline$\cdot, \cdot r_{1}$ & $0, r \mid r$ & $\cdot, \cdot \leq r$ & $\cdot, .91$ & 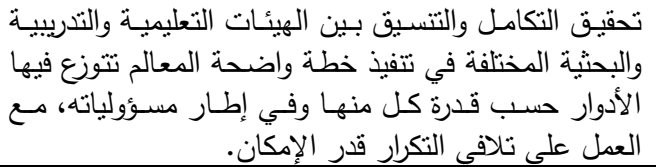 & $r$ \\
\hline$\cdot, \cdots$ & $7,9 \wedge 9$ & $\cdot, \cdot \Sigma \cdot$ & $\cdot, Y \wedge Y$ & 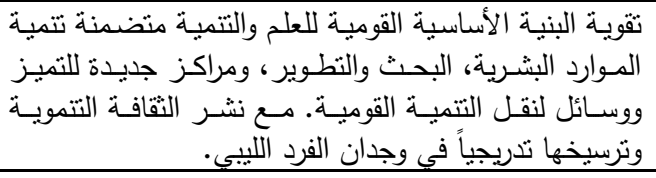 & $\varepsilon$ \\
\hline$\cdot, \cdots$ & $\varepsilon, Y \backslash 7$ & $\cdot, \cdot r_{1}$ & $\cdot, 111$ & 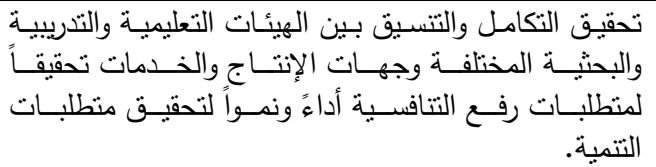 & 0 \\
\hline$\bullet, \cdots$ & $\varepsilon, 001$ & $\cdot, .0 Y$ & $\cdot, \leqslant 09$ & 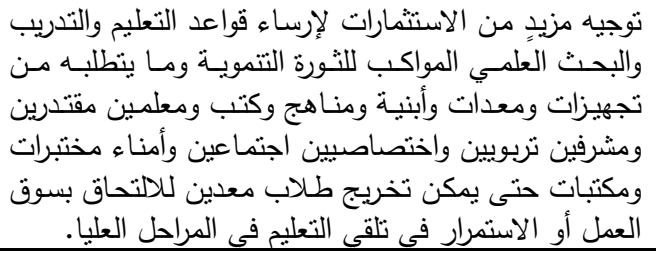 & 7 \\
\hline$\cdot, \cdots$ & $0, Y \backslash \leq$ & $\cdot, .07$ & • & 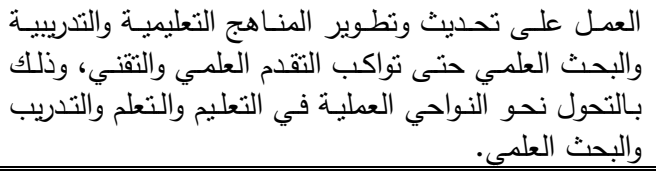 & V \\
\hline
\end{tabular}


تابع جدول رقم(9): درجة تأثثر إعادة صياغة برامج وسياسات إدارة الموارد البشرية مع تضمينها العناصر المرتبطة بالتفاعل مع معطيات التنمية العلمية والتتموية، وعلى زيادة قدرة قطاع التعليم على مواجهة التحديات الحالية والتعامل مع الفرص المستقبلية لهذه التتمية.

\begin{tabular}{|c|c|c|c|c|c|}
\hline 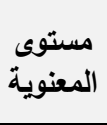 & قيمة & 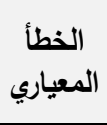 & $\begin{array}{c}\text { الانحدار } \\
\beta \\
\beta\end{array}$ & المتغير & \\
\hline$\cdot, \cdots$ & $r, 1 \ldots$ & $\cdot, \cdot \vee V \varepsilon$ & $\cdot, Y \circ \Lambda$ & 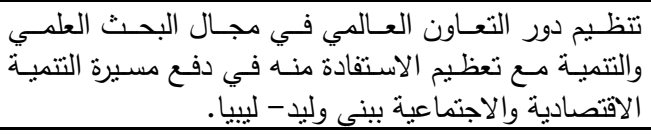 & $\wedge$ \\
\hline$\cdot, .19$ & $r, \mid r r$ & אזי,. & $\cdot, .91$ & 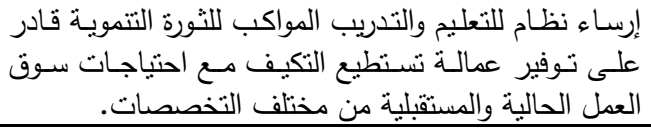 & 9 \\
\hline$\cdot, \cdots$ & r,१११ & $\cdot, \cdot \leq r$ & $\cdot, Y 10$ & 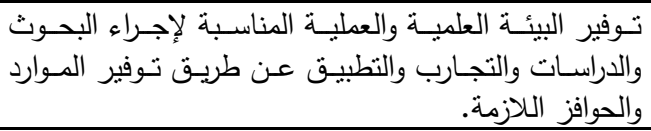 & 1. \\
\hline$\cdot, \cdots$ & $7, r \wedge q$ & $\cdot, \cdot \leq r$ & $\cdot, 10$ & 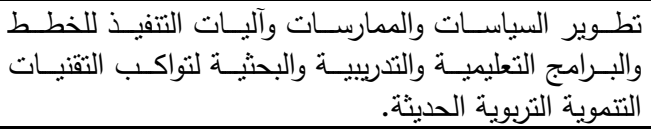 & 11 \\
\hline$\cdot, \cdots$ & $0,1 \leqslant V$ & $\cdot, .0 r$ & $\cdot, \leqslant 09$ & التنمية على مخلى إنشاء مراكز معلومات التخصصات قومية تواكب منطلبات & Ir \\
\hline$\cdot, .19$ & $r, 1<q$ & $\cdot, .0$ & • & 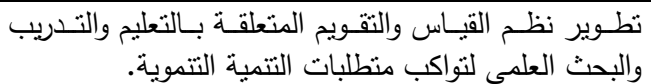 & $\pi$ \\
\hline$\cdot, \cdots$ & $0,1 Y \varepsilon$ & $\cdot, \cdot r_{T}$ & $\cdot, \cdot 71$ & 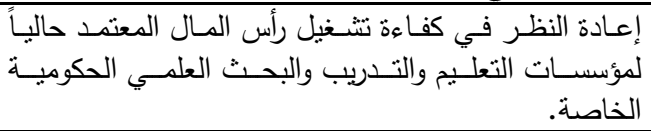 & $1 \varepsilon$ \\
\hline$\cdot, \cdots$ & $r, \cdot 11$ & $\cdot, \cdot$ TV & $\cdot, 174$ & الالارتقاء بهـاء بمسـتوى التعلـيم وزيـادة مرونتـه، مـع رفـع نسـبة & 10 \\
\hline$\cdot, .19$ & $1, \cdots r$ & $\cdot, \cdot \leq r$ & $\cdot, r \ldots$ & 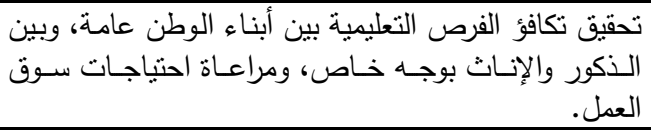 & 17 \\
\hline$\cdot, \cdots$ & $1, \cdot v \leqslant$ & $\cdot, .0 r$ & $\cdot, \leqslant 09$ & 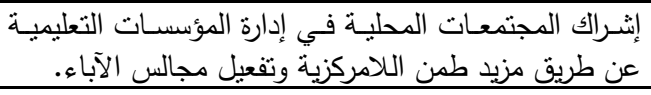 & IV \\
\hline$\cdot, \cdots$ & $1, r 10$ & $\cdot, \cdot Y_{T}$ & $\cdot,+71$ & 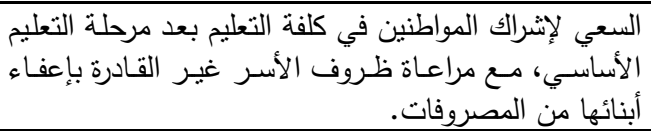 & 11 \\
\hline
\end{tabular}


تابع جدول رقم(9): درجة تأثير إعادة صياغة برامج وسياسات إدارة الموارد البشرية مع

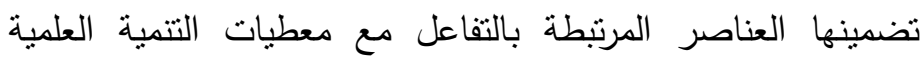
والتتموية، وعلى زيادة قدرة قطاع التعليم على مواجهة التحديات الحالية والتعامل مع الفرص المستقبلية لهذه التتمية.

\begin{tabular}{|c|c|c|c|c|c|}
\hline المعنوية & ق قيمة & 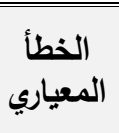 & الانحدار & \multicolumn{2}{|l|}{ المتغير } \\
\hline$\cdot, \cdot 19$ & $1, \cdot+1$ & $\cdot, \cdot T V$ & •,IKr & 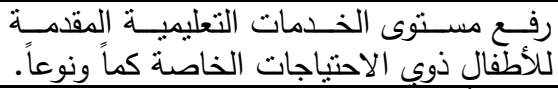 & 19 \\
\hline$\cdot, \cdots$ & $1, \cdot \vee 9$ & $\cdot, \cdot \varepsilon$. & $\cdot$, YO & 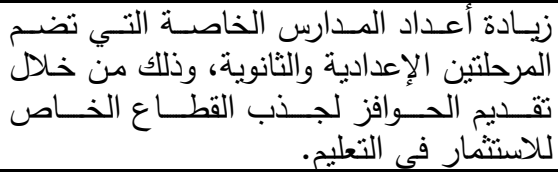 & $r$. \\
\hline$\cdot, \cdots$ & 1, AOr & Tr & $\cdot, 199$ & 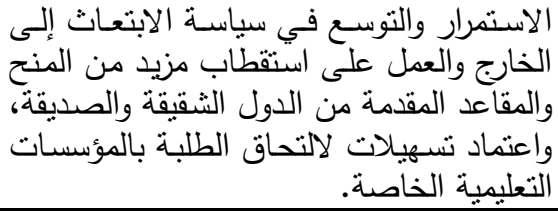 & YI \\
\hline$\cdot, \cdots$ & $1, \cdot T \varepsilon$ & $\cdot, .0$ & $\cdot, \mid Y$. & 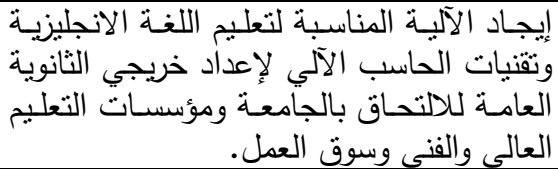 & Yr \\
\hline$\cdot, .19$ & $1, \cdot r_{0}$ & $\cdot, \cdot r 4$ & $\cdot, \cdot 71$ & 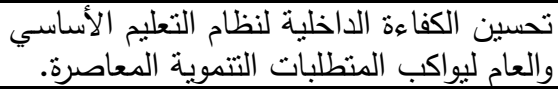 & $r T$ \\
\hline$\cdot, .19$ & $r, Y 04$ & $\cdot, \cdot \leq r$ & $\cdot, r \leq \varepsilon$ & قدرتها والارنقاء بـالقوى البشــرية وإنتاجيتهــا وزيــادة & $r \varepsilon$ \\
\hline$\cdot, \cdots$ & $0, Y \backslash \leqslant$ & $\cdot, .0 Y$ & $\cdot, 111$ & 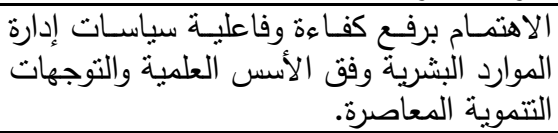 & TV \\
\hline$\cdot, \cdots$ & $\varepsilon,|Y|$ &., .0 . &., 101 & الإجمالي & \\
\hline
\end{tabular}




\section{النتائج}

1- القصور الواضح في منظومة البحث العلمي من حيث الخطط والبرامج والأساليب والمناهج

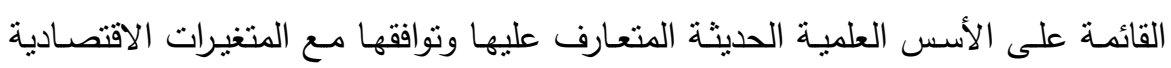

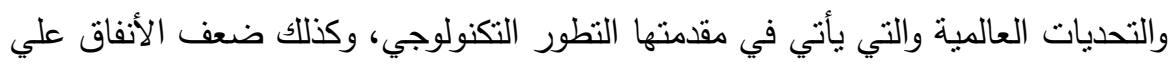

$$
\text { البحث العلمي. }
$$

ץ- توجد علاقة طردية موجبة بين كل من بناء خطط وبرامج التعليم المواكبة للثورة التعليمية التتموية وبين كفاءة سياسات إدارة الموارد البشرية في مواكبة متطلبات هذه هونه التتمية. r- الارتباط في أعلي قيمة له بالنسبة لتفهم المسؤولون بقطاع التعليم بليبيا بأهمية بناء خطط

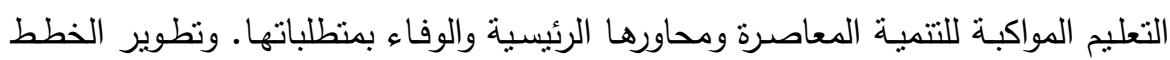

$$
\text { والبرامج والمناهج التعليمية وفق المستجدات التتموية المنطورة. }
$$

ع - الارتباط في أدنى قيمة له بالنسبة بما تتسم بـه المناهج التعليمية بمدارس التعليم المنتشرة

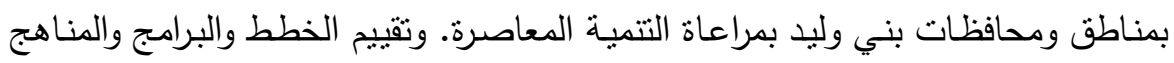
التعليمية بليبيا وفق محاور ومتطلبات التتمية المعاصرة و درجة ارتباطهما بفاعلية عملية سياسات إدارة الموارد البشرية أقل تأثثراً من العناصر الأخرى.

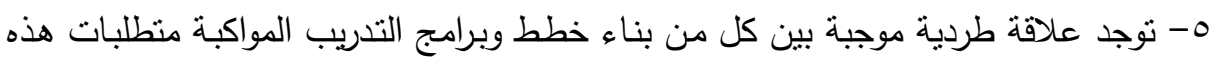

1- الارتباط في أعلى قيمة بالنسبة لتفهم المسؤولين بقطاع التعليم بني وليدـ ليبيا بأهمية بناء

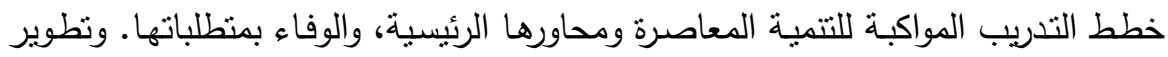
الخطط والبرامج والمناهج التدريبية وفق المستجدات التنموية المتطورة.

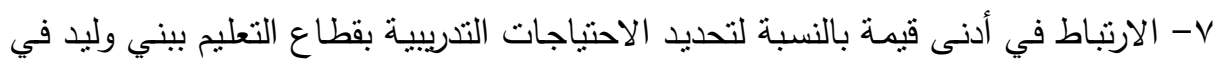

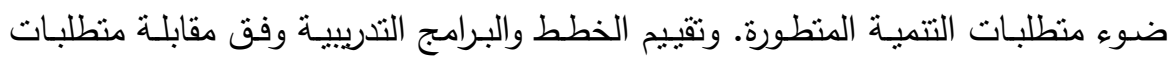
التتمية المعاصرة ، وتوفير بيئة العمل الملائمة لتطبيق البرامج التدريبية والمواكبة لمتطلبات التتمية مما يؤدي إلى تعظيم العائد التدريبي، ودرجة ارتباطهما بفاعلية عملية سياسـات التئه إدارة الموارد البشرية أقل نأثيراً من العناصر من العند الأخرى. 
^-توجد علاقة طردية موجبة بين كل من بناء خطط وبرامج البحث العلمي المواكبة التتمية وبين كفاءة سياسات إدارة الموارد البشرية في مواكبة متطلبات هذه التتمية.

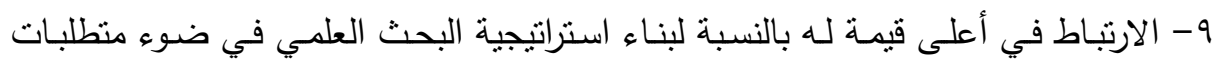
التتمية المعاصرة. وتطوير الأبحاث العلمية وفق المستجدات التتموية المتطورة.

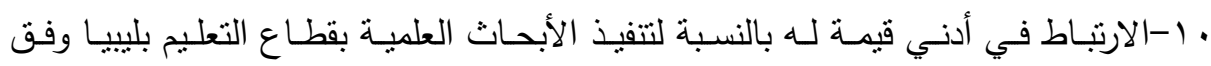

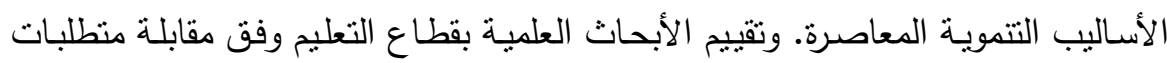

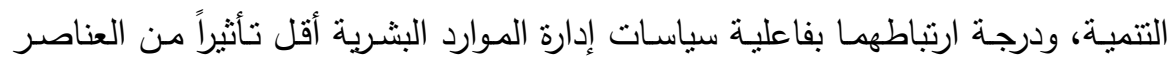

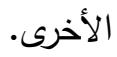

1) - توجد علاقـة طرديـة موجبـة بين كل مـ الاستتمارات الموجهة لخطط وبرامج التعليم المواكبـة لتتميـة وبين كفاءة سياسـات إدارة الموارد البشـرية بقطاع التعليم بليبيافي مواكبـة متطلبات هذه التتمية.

r ا - الارتباط كان في أعلى قيمة له في توفير المباني و المعدات والأجهزة والوسائل العلمية والتعليمية المواكبة لتتمية المعاصرة. وتطوير الخطط والبرامج والمناهج التعليمية المواكبة ولية للتتمية المعاصرة. r ا - الارتباط في أدنى قيمة لـه بالنسبة لتوفير مراكز معلومات تعليمية لمحاور ومتطلبات

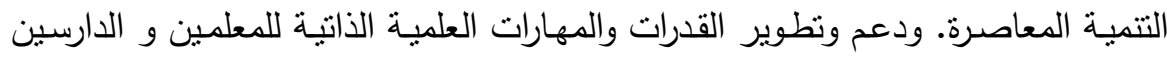

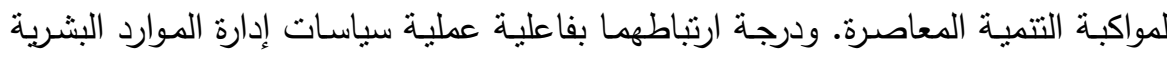

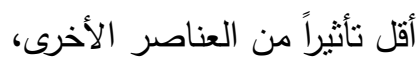
ـ ا- توجد علاقة طرديـة موجبة بين كل من الاستثمار الموجهة لخطط و برامج التدريب

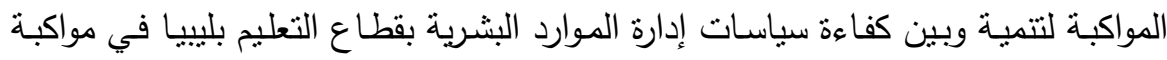
متطلبات هذه التتمية.

1 - الارتباط كان في أعلى قيمة في توفير المباني والمعدات والأجهزة والوسائل التدريبية

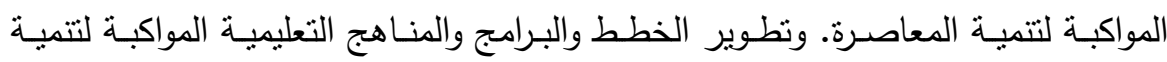
المعاصرة. 
7 ا 1 - الارتباط في أدنى قيمة له بالنسبة لإيجاد الأليات المناسبة لمتابعة وتتفيد وتقييم نشاط ذاته ومدى ملاعمته لتتمية المعاصرة. ودعم وتطوير القدرات والمهارات التدريبية والذاتية

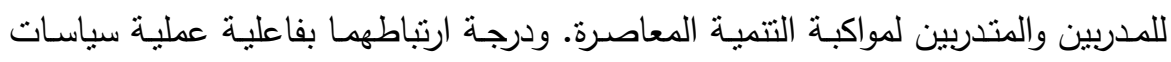

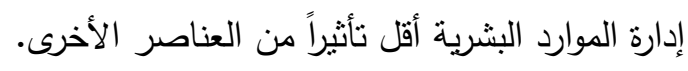

V ا توجد علاقة طرديـة موجبة بين كل من الاستثمارات الموجهة لخطط وبرامج البحث

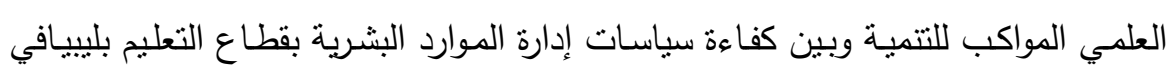
مواكبة متطلبات هذه التتمية.

1 ا - الارتباط كان في توفير المباني والمعدات والأجهزة والوسائل اللازمة للاراسات والبحوث

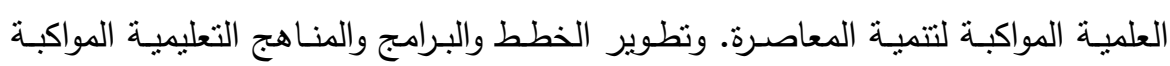
لتنمية المعاصرة..

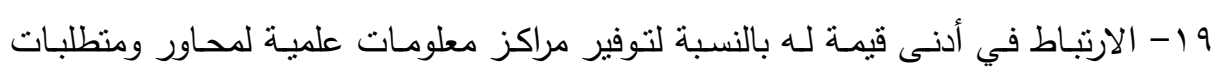

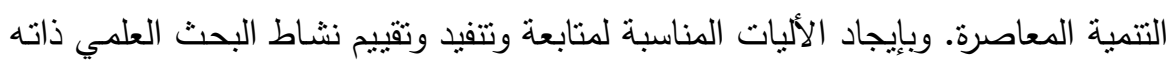
ومدى ملاعمته لتتمية المعاصرة. ودرجة ارتباطهما بفاعلية عملية سياسـات إدارة الموارد البشرية أقل من العناصر الأخرى.

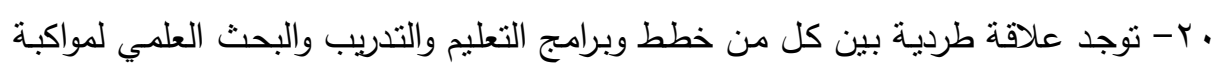

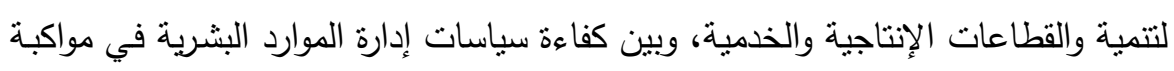
متطلبات هذه التتمية.

ا آ- الارتباط كان في أعلى قيمة له بالنسبة لتوفر سياسات علمية وتتموية واضحة وشاملة

$$
\text { ومسايرة التحولات المعاصرة. وكبر الفائدة من الاتفاقات الدولية. }
$$

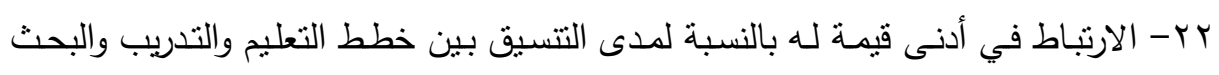

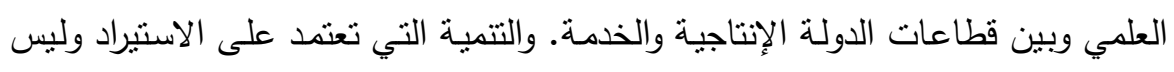

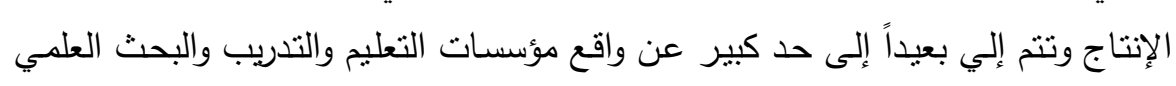

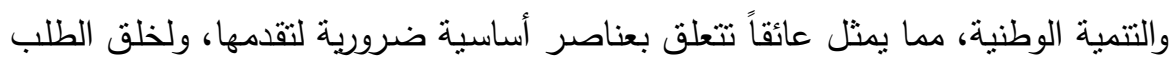

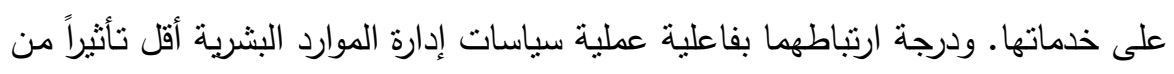

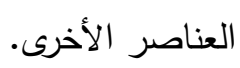


r ب - توجد علاقة مجوبة بين إعادة صباغة برامج وسياسات إدارة الموارد البشرية مع تضمينها

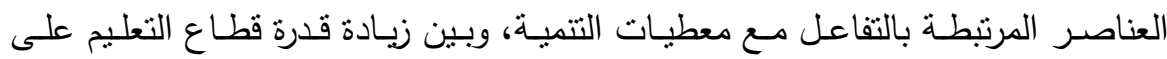
مواجهة التحديات الحالية والتعامل مع الفرص المستقبلية لهذه التتمية. ع r- توجد علاق طردية موجبة بين تحقيق التكامل والتتسيق بين الهيئات التعليمية والتدريبية والبحثية المختلفة في تتفيذ خطة واضحة المعالم تتوزع فيها الأدوار حسب قدرة كل منها

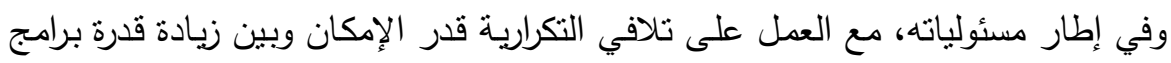
وسياسات إدارة وتتمية الموارد البشرية على مواكبة التتمية.

\section{التموسيامت والمهيمباته}

1-يجب على قطاع التعليم، النظر إلى الأفراد كعنصر استراتيجي لنجاح قطاع التعليم وتنبي

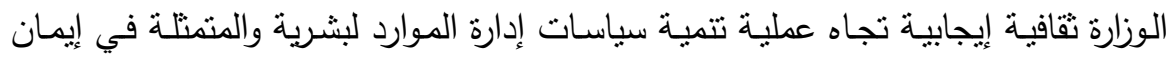

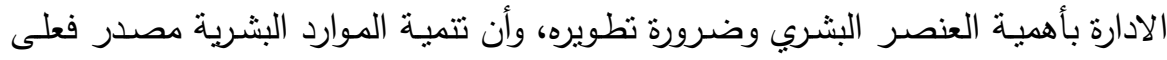
من مصادر العائد على رأس المال المستثمر ، ومواكبة التتمية المعاصرة. r- لابد على قطاع التعليم العمل على تطوير الوضع التظيمي لإدارة الموارد البشرية، بحيث

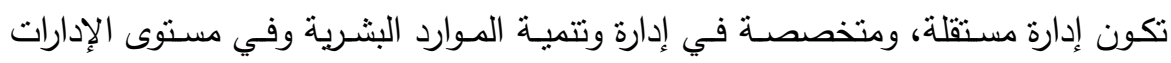

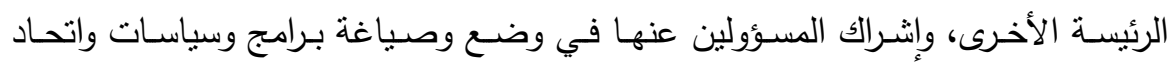

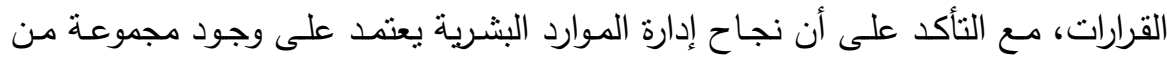

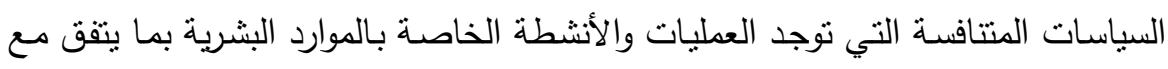
أهداف المنظمة من ناحية و المفاهيم الجديدة لإدارة الموارد البشرية من ناحية أخرى.

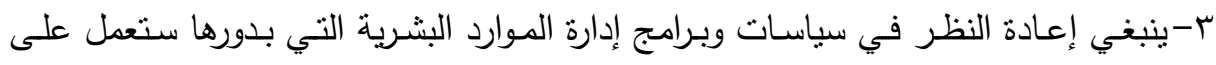
إحداث التغير الحقيقي في القدرات البشرية.

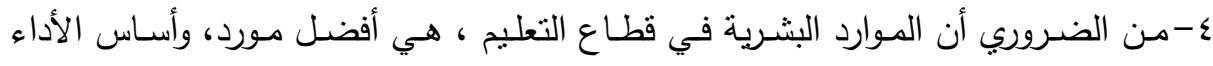

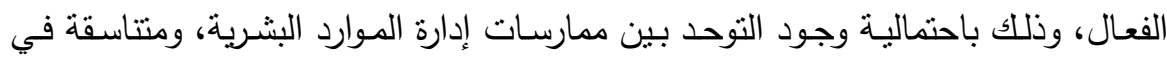

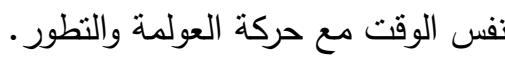


ه-ضـرورة اعتبار التعليم والتدريب والبحث العلمي والتتميـة التكنولوجيـة أهم وسـائل تحقيق

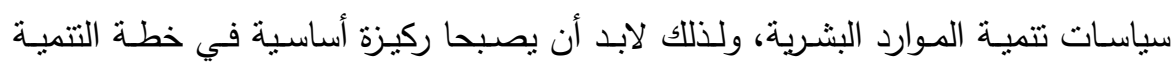
القومية

1-تحقيق التكامل والتتسيق بين الهيئات التعليمية والتدريبية والبحثية الدختلفة، وجهات الإنتاج والخدمات تحقيقاً لمنطلبات رفع التتافية اداءً ونمواً لتحقيق منطلبات التتمية.

V- على قطاع التعليم توجبه مزبد من الاستثمار لإرساء قواعد التعليم والتدريب والبحث العلمي مئه

$$
\text { المواكب لتتمية. }
$$

^- التأكيد على تحديث وتطوير المناهج التعليمية والتدريبية والبحث العلمي وربطها بسياسات تتمية الموارد البشرية المواكبة التتمية.

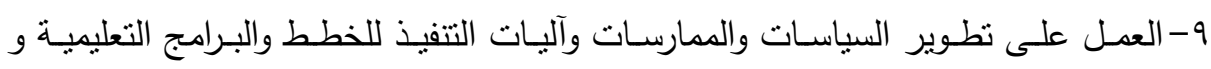
التدريبية والبحثية لتواكب الثقنيات التكنولوجية التربوية الحديثة.

\section{المراليج}

إبراهيم قويدر ( ( . ؟ ): تتمية الموارد البشرية وسياسات خلق فرص عمل جديدة، منظمة العمل

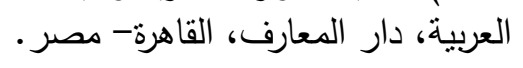

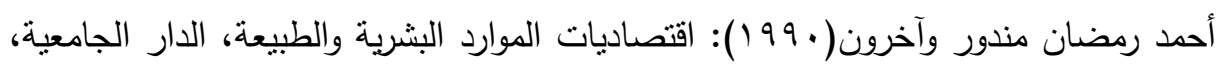
(بيروت - لبنان).

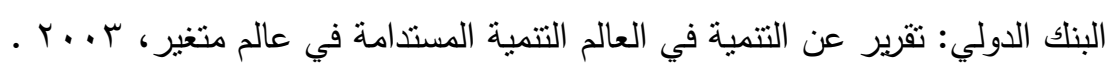

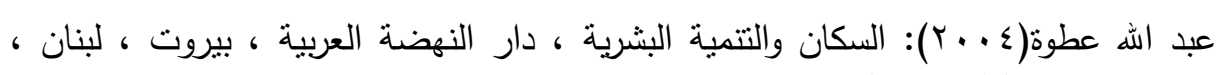

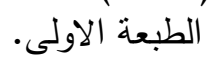

ماهر بيتر حنا(·99 (1): عرض مؤشرات تقدير درجة فاعلية التتمية الاقتصادية مع الاثارة

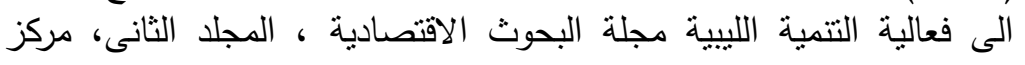

$$
\text { العلوم الاقتصادية ، بنغازى ، لبيا. }
$$

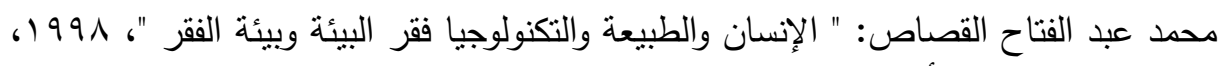

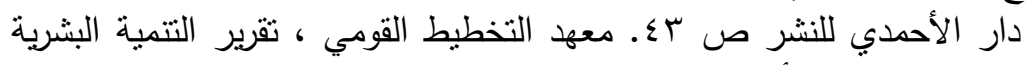

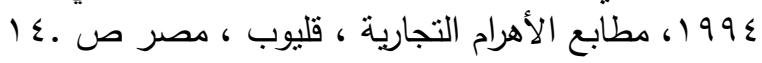

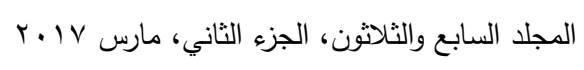


Adam Smith (2005): An Inguiry into the Nature and causes of the wealth nations. Pennsylvania. State university. USA. Chapter. VIII. P58.

T.W.Schultz (1961), Investment In human Capital . A.E.R (American economic review) Vol 51. No.1, March 1961, P.P 1-17.

\title{
THE DEVELOPMENT OF HUMAN RESOURCES AND
}

THEIR ROLE IN ACHIEVING SUSTAINABLE

DEVELOPMENT

\section{SPECIAL STUDY ON EDUCATION SECTOR IN BANY}

WALID - LIBYA

Mandour, A. F. ${ }^{(1)}$; Tadros, Safaa, G. ${ }^{(1)}$; Amaar M. M. ${ }^{(2)}$

Saleh, Omalsaad, $M$.

1) Faculty of Commerce, Ain Shams University 2) Faculty of Economics and Political Science, Al-Fateh University

\begin{abstract}
The sustainable development process is a process includes human development for the purpose of improving level of health care and education in addition to participation in of people in developmental decision-making that affect their lives; added to that the element of justice, fairness, and equality. There are two types of fairness. Fairness to the coming generations and fairness towards those who are living at present and have needs and suffer from inequality in obtaining natural resources or social services. Sustainable development also drives at promoting opportunities of education and health care.

The concern in the connection between human development and concept of sustainable development is evidently increasing, as there is a 310

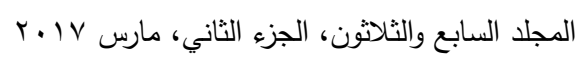


critical need for making balance between population on one hand and the available resources on the other hand, it is a relationship between present and future to guarantee a better life for coming generations. That is why the environment issues should everlasting be associated to development as there is no sustainable development without human development.

This study discusses the great role the development of human resources play to achieve sustainable development, since human resources are the factor determining targets and policies, it is also the factor sets plans and programs and bear the responsibility of directing and utilizing the optimal use of potentials and available concrete resources. So, the investment in human resources is achieved through education which is an important and fundamental part of building up human potentialities and skills effectively. Education represents a basic resource for all developmental plans and a basic pillar of sustainable development.

The researcher follows the descriptive method in analysis by collecting data, information, and statistics due to sex (male/female), educational certificate (university certificate - post graduate - above middle - middle - less), and age stage (21-31, - 30-40, 41-51, 50-60). The study sample consist of (100) items. It also uses the statistical method.

The study results indicate that there exists shortness in the scientific research system regarding plans, programs, approaches, and methods that are based on science and cope with economic changes and global challenges. There is a direct positive relationship between building education programs and plans and efficiency of human resources management policies.

The study recommends considering education, training, scientific research and technological development as the most important means for achieving policies of human resources development; recommending also raising the competitiveness of performance in order to achieve demands of growth, developing as well the educational curricula, training, and the scientific research to be connected to policies of human resources development.

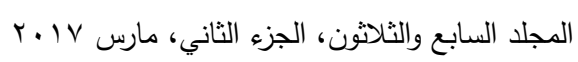

